\title{
A Green Quality Management Decision Model with Carbon Tax and Capacity Expansion under Activity-Based Costing (ABC) - A Case Study in the Tire Manufacturing Industry
}

\author{
Wen-Hsien Tsai \\ Department of Business Administration, National Central University, Jhongli, Taoyuan 32001, Taiwan; \\ whtsai@mgt.ncu.edu.tw; Tel.: +886-3-4267247
}

Received: 22 May 2018; Accepted: 12 July 2018; Published: 16 July 2018

\begin{abstract}
Issues related to global environmental protection are highly important. Under the global trend of energy saving and carbon reduction, in order to lower the carbon emissions of products or services offered by enterprises, the Taiwanese government aims to control carbon emissions by constructing a carbon tax system and mandating enterprises to pay a carbon tax. The collection of a carbon tax can minimize the total social environmental cost and increase the efficiency of carbon reduction; the need to control the green quality cost can serve as a criterion of green management decision-making. This study aimed to reorganize carbon emissions in different stages of production in order to lower the total carbon emissions of products. Activity-based costing (ABC) was adopted to assess green quality management and production cost. The optimal green quality production portfolio was selected via a mathematical programming model to focus on the expansion of productivity and outsourcing strategy in order to effectively lessen the harmful effects on the environment and maximize profits. Besides academic contributions, the findings of this study could serve as a reference to enterprises on assessing the effects of carbon emissions, carbon taxes, and environmental management on production decision-making.
\end{abstract}

Keywords: carbon emissions; carbon tax; activity-based costing ( $\mathrm{ABC}$ ); capacity expansion; green quality management; product-mix decision model; mathematical programming

\section{Introduction}

Issues regarding climate change have received increased attention in recent years. The misuse of natural resources by human and industrial activities affect the balance of the life cycle sustained by Earth and cause abnormal weather and global warming. It is the goal for every nation to stop exhausting greenhouse gases (GHG) for the Earth to provide a sustainable growing environment. In May 1992, the United Nations Framework Convention on Climate Change (UNFCCC) was adopted. It aimed to control the concentration of greenhouse gases in the atmosphere to "a level that would prevent dangerous anthropogenic interference with the climate system" [1]. Developed economies took responsibility for environmental protection through forming international organizations or signing protocols such as the Copenhagen Accord [2], the Kyoto Protocol [3], and the Paris Agreement [1]. Developed economies use these agreements as self-discipline or criterions for countries around the world to balance economic growth and environment protection. In addition, they recognize that these agreements will significantly reduce the risks and impact of climate change and meet the objective of "making finance flows consistent with a pathway towards low greenhouse gas emissions and climate-resilient development" [1]. 
Green Quality Management mainly aims at eco-efficiency in the complete product life cycle, including design, raw material selection, process improvement, prevention and treatment of pollution, after-sales services and waste recycling, and processing. Quality cost measurement is the first step of quality cost management. Several researchers have proposed various methods to measure the cost of quality (COQ), which includes prevention, appraisal, internal failure, and external failure costs [4]. The Activity-Based Costing ( $\mathrm{ABC}$ ) approach has been widely used in measuring COQ [5-9] because many COQ elements are activity-related costs [9]. ABC uses a two-stage cost assignment to compute the costs of activities in the first stage and the costs of the objects in the second stage [10]. Thus, activity costs can be achieved in the first stage and sources of activity costs can be traced in the second stage of $\mathrm{ABC}$ cost assignment. $\mathrm{ABC}$ divides activities into value-added (VA) and non-value-added (NVA) activities. The purpose of green quality management is to reduce the workload of VA activities and to finally eliminate the execution of NVA activities related to COQ.

The theory of constraints (TOC), proposed by Goldratt in the book titled "The Goal" [11], aims to identify the constraints and managing them. There are several constraints in business operations, and TOC uses five steps to identify and eliminate the bottlenecks one by one to increase business performance. One method is capacity expansion with a fixed capital investment to increase the possible sales and profits.

Carbon taxes aim to reduce carbon emissions, and they offer a potentially cost-effective means of reducing greenhouse gas emissions [12]. Carbon taxes are also an important policy tool for environmental protection to prompt companies to pursue optimal environmental management under tax considerations [13-15]. Currently, carbon taxes are assessed differently from country to country due to variances in environmental policies, so companies must incorporate them in their production and pricing decisions $[16,17]$.

In view of the above discussion, the purpose of this paper was to propose a green quality management decision model with the consideration of carbon taxes and capacity expansion under $\mathrm{ABC}$. This study took the tire industry as an example to illustrate the application of the model presented in this paper. In addition to considering factors such as carbon taxes, capacity resource limitations, and market demand, this study also took the emissions reduction of pollution during the production process into account. This study combined models of TOC, ABC, green quality management and capacity expansion and used mix-integer programming (MIP) to find the optimal product mix and its resource consumption analysis as a basis for green decision-making. In addition, this paper also discussed how the production plan, derived from the green quality management decision model, can be executed with the help of Industry 4.0 techniques. The remainder of this paper is organized into four sections. Section 2 details the literature about the concepts of environmental management under intelligent manufacturing and the production flow in the Tire industry. Section 3 presents the research method. The green quality management decision model is developed in Section 4. A numerical example is used to demonstrate how to solve these models with MIP and sensitivity analysis under the consideration of carbon taxes and capacity expansion in Section 5. Finally, discussions and conclusions are presented in Sections 6 and 7, respectively.

\section{Green Quality Management in the Tire Manufacturing Industry}

\subsection{Green Quality Cost Management}

The purpose of green quality cost management is to find, identify, and quantify the direct and indirect environment-related costs in production so as to help improve the environmental performance of enterprises, realize cost control, evaluate investments in equipment and technology of clean production and pollution prevention and treatment, and develop better processes and green products according to the concept of environmental protection and clean production [6]. Further, it may provide valuable information for decision makers in terms of product structure, retention, and pricing strategies, etc. Green quality cost data can provide important indicators to evaluate the environment 
quality of enterprises, and can also play an essential part in determining whether the green quality cost management system is effective or not. Objective standards are provided to determine whether the green quality management cost stays aligned with the purpose of environmental protection. Green quality management cost consists of the prevention cost, appraisal cost, internal failure, and external failure cost [9].

The preventive activities of green production quality management are intended to establish a mechanism of enhancing green quality awareness and preventing the impact on the environment. It reduces the negative impact of products during the life cycle on the environment. The prevention cost refers to all expenses incurred in this process and mainly includes green quality planning and renovation projects, green brainstorming activities, the analysis of green process capacity, and green product design, etc. The prevention cost consists of relevant expenses incurred when preventing environmental pollution during production and service activities [18].

Appraisal activity costs refer to all expenses incurred in determining whether the prevention measures achieve the anticipated goals or outcomes. From the design of the product life cycle to the first delivery of goods, the evaluation and assessment activities mainly focus on those which fail to satisfy the green standards. The appraisal cost assures product specifications and quality in the production process based on the quality standards. The appraisal cost includes the necessary expenses on green quality standards tests such as environment check and testing expenses, the purchase of materials and process examination fees, as well as quality checks and diagnostic products tests, etc. [9].

Internal failure activity costs refer to the costs and losses incurred when the products have defects and fail to meet the green quality standards after production but before delivery [19]. Internal failure costs include the cost of reproduction, losses from waste, damaged products, failure analysis, and reexamination due to the failure of meeting the green standards and quality standards $[19,20]$.

External failure activity costs refer to the costs and losses incurred when the products have defects and fail to meet the green quality standards after delivery. External failure costs include the cost of after-sale service and warranties, any penalties and compensation incurred due to the failure of observing relevant laws and regulations in the process, any unexpected expenses from the disposal of waste, and the reduction of operating income resulting from negative public images regarding environmental protection, etc. [21].

\subsection{Production Flow in the Tire Industry}

Figure 1 shows the tire production flow chart. There are four main activities, as shown below:

(1) Mixing and Component preparation: First, natural rubber, processed oil, carbon black, and other chemicals are mixed into a compound using a Banbury mixer, which is then squeezed into a thin sheet using extruders. Other components include fabric calendar transferred from textiles and fabric, and wire calendar, steel calendar, bead, and belt transferred from steel.

(2) Tire building: The tire building machine pre-shapes radial tires into a form very close to their final dimensions to make sure the many components are in their proper positions before the tire goes into the mold.

(3) Curing press: The curing press is where tires attain their final shape and tread pattern. Hot molds shape and vulcanize the tire. The molds are then engraved with the tread pattern and sidewall marking.

(4) Tire inspection: Trained inspectors perform a visual inspection to check the tire surfaces. A balance inspection and force variation are then carried out to check uniformity. Finally, some tires are sampled from the production line and X-rayed to detect any hidden weaknesses or internal failures. In addition, quality control engineers regularly perform cut sections and study details of the tire construction that affect performance, ride, or safety [22]. 




Figure 1. Tire production flow chart.

\subsection{Shop Flow Control and ABC Costing with the Help of Industry 4.0}

\subsubsection{Origin and Meaning of Industry 4.0}

The era of Industry 4.0 is coming for the global manufacturing industry. This is the biggest change since the third industrial revolution in 1970. Automated production has been upgraded to the level of intelligent manufacturing [23], which is also called the fourth industrial revolution. The concept of Industry 4.0 was first mentioned at the Hannover Fair in 2011. It means to apply the Internet of Things and system service applications into the production process to become a cyber-physical production system [24]. It vertically integrates production factors such as materials, human resources, equipment, and factories to form an intelligent manufacturing network and, at the same time, horizontally integrates the value chains of supply vendors and customers as a value creation network and reduces pollution and greenhouse gas emissions during production as much as possible [25].

Industry 4.0 places emphasis on its products' influences on the environment by taking advantages of different concepts of a smart factory, which include green production, intelligent production and urban production. Meanwhile, big data is adopted to analyze corporate conditions and resources to guide enterprises with environmentally friendly guidelines during their development of innovative green technology [26] so that they can make efficient use of resources, reduce costs, and relieve the impact of operating activities on the environment in current and expanding production.

Under Industry 4.0, virtual models based on the orders of customized tires are produced according to the advice of existing experts and product design and processing knowledge on the cloud through the Internet [27]. Then, the physical products are put into production based on the model and a production schedule is made. A virtual production system control workshop is built and robotic arms take the place of a traditional workforce in the production of tires by applying automatic assembly and sensors/actuators in the virtual workshop to the production process [28]. The production data are sent to the cloud database as digital knowledge accumulation.

\subsubsection{Collecting Data for $\mathrm{ABC}$ Costing Using Industry 4.0 Techniques}

In the past, enterprises were in pursuit of high quality with the most appropriate costs in the shortest production cycle and lead time, and they made dramatic investments in the establishment of mechanisms and production management systems, as well as automation. Although they might have had knowledge of existing problems through various information dashboards, they failed to make full use of the databases of those systems and the valuable information in the systems. In order to integrate the goals of multiple systems and keep those goals in line with their corporate mission, enterprises need to combine data mining technology and the intelligent analysis methods of specific fields and identify key opportunities for breakthroughs from massive amounts of data [29]. As Industry 4.0 
and the era of the Internet of Things approach [30], with the help of wider usage of information extraction technology through the Internet and cloud computing, integration of both upstream and downstream information can be easily realized in combination with an automatized factory system. Intelligent manufacturing will be a niche market that can cater to customers' demands in the future [31]. In addition, sensors/actuators, high-performance computing systems, and the production control of intelligent factories will manage to detect various available production capacities in a short time and arrange configurations correspondingly and effectively, which avoids inadequate production.

Technically speaking, intelligent factories emphasize mobile sensors/actuators and artificial intelligent self-organized machine learning [26]. At the same time, they give full play to the mature computing virtual technology to accomplish the integration of manufacturing and service in the vertical activities of corporate entities and further improve the support of relevant activities of enterprises.

Big data for production emphasizes the digitalization of all information, from product design to after-sales service. With the necessary information for cost analysis available on the cloud system, and by combining the theory of constraint with the expansion of production capacity and the system of fundamental operating costs, enterprises can oversee the resource consumption and carbon emissions of each activity. Through virtual design and analysis of the virtual factory, real-time cost analysis results and a review of the carbon footprint can be provided before production, which can reduce the number of potentially damaged products, reproduced products, and carbon emissions during the production of physical products.

In summary, Industry 4.0 uses cyber-physical systems (CPS) and the Internet of Things (IoT) [13] to link all the elements in the production system. Then, the system will real-timely collect and monitor the activity data of all the elements and send out intelligent responses to various problems that may arise in the manufacturing spots according to the real-time analysis results of big data and cloud computing. Finally, the production process can be flexibly adjusted or set up differently on the basis of specific customer needs to attain the objectives of mass customization and customer satisfaction. The activity cost calculation and activity improvement of Activity-Based Costing (ABC) can be easily achieved since all the elements in the manufacturing systems can be integrated and monitored under Industry 4.0 .

\section{Research Method}

\subsection{TOC and Capacity Expansion}

First proposed by Goldratt [11], TOC is mainly used to resolve short term product mix and processing bottleneck resource problems. It is an improved method of the conventional cost accounting system that hinders the effective output of a company, arguing that all organizations have restrictions that will affect the activities of the entire organization. Paraskevopoulos, Karakitsos and Rustem [32] held that the expansion of production capacity should also be included in the production plan when uncertainties emerge in the production environment so that the production capacity can be adjusted if there are any changes in the external environment. They found that the bottleneck factors determine the level of product mix flexibility, and that bottleneck improvements make a better contribution than non-bottleneck improvements.

Targeted at the present operating process and production level, the theory of constraints explores the best management method. However, for decision-making about long-term production, the production capacity of each activity must be specifically planned. When confronted with gaps in the production capacity, enterprises should adopt different strategies to expand production capacity in order to meet demands, such as recruiting new employees, purchasing more equipment, outsourcing, working overtime, or renting equipment. Aghezzaf [33] proposed that production capacity does not merely mean the production capacity of the equipment but also the available workforce in each period, which should be given high priority and taken into consideration to develop a series of efficient algorithms for human resource schemes based on strategies. When the production capacity of human 
resources is calculated, the results should be transferred into the production capacity for both regular time and overtime. Kok [34] indicated that when demands surpass the available production capacity, two strategies of production capacity, including postponing and outsourcing, should be utilized to build a mathematical model. Then, the enterprises can choose the best strategy with lower costs and other relevant parameters between the two strategies.

\subsection{Green Quality Cost Measurement under ABC}

Kaplan and Cooper first proposed ABC in 1988 to overcome the distortion of the conventional cost accounting system [35]. ABC uses a two-stage cost assignment method and considers resource drivers and activity drivers as the bases of cost assignment, as shown in Figure 2. ABC assumes that cost objects (e.g., products, product lines, processes, customers, channels, and markets, etc.) create the need for activities, and that activities create the need for resources. Accordingly, ABC uses a two-stage cost assignment method to assign resource costs to cost objects. In the first stage, resource costs are assigned to various activities by using resource drivers. Resource drivers are the factors that approximate the consumption of resources by the activities. The appropriate resource drivers are determined according to the analysis of the correlation between resources and activity costs [36]. Each type of resource traced to an activity becomes a cost element of an activity cost pool. Thus, an activity cost pool is the total cost associated with an activity. An activity center is composed of related activities that are usually clustered by function or process. It is possible to create activity centers by various ways according to different information needs [9].

In the second stage, each activity cost pool is distributed to the cost objects using an adequate activity driver which is used to measure the consumption of activities by the cost objects [10]. If the cost objects are products, then the total cost of a specific product can be calculated by adding the direct material cost and the direct labor cost, as well as the costs of various activities assigned to that product [9]. At the second stage, the appropriate activity drivers are determined according to different activity levels (e.g., unit-level, batch-level, process-level, product-level, or facility-level) in order to summarize the cost databases before attributing costs to the cost objects, thus obtaining reliable cost assignment information [10,36]. Unit-level activities are performed one time for one unit of product, e.g., 100 percent inspections, machining, or finishing, etc. Batch-level activities are performed one time for a batch of products, e.g., sampling inspections, set-up, or scheduling, etc. Process-level activities are performed to sustain the operations of a process, e.g., the various tasks executed in a process. Product-level activities are performed to benefit all units of a particular product, e.g., product design, design verification, or review, etc. Facility-level activities are performed to sustain the manufacturing facility, e.g., plant guards and management, or zero defect programs, etc. [9].

Kaplan and Cooper argued that $\mathrm{ABC}$ emphasizes the relationship between the activities and the consumption of resources; therefore, it can provide product decision-making information and help managers with decisions regarding product design, pricing, product mix, marketing, and process improvements [35]. $\mathrm{ABC}$ provides information in the recognition of activities that cause poor quality by classifying all activities as either value-added (VA) or non-value-added (NVA) activities. According to this categorization, VA activities are those that contribute to the value (increase the quality and effectiveness of use) of the product/services delivered. As NVA activities do not contribute to the value of the product/services, their elimination decreases the related costs and has no effect on the value of the products/services $[9,37]$. As ABC can provide an effective and complete estimation of product costs, enterprises may use $\mathrm{ABC}$ and calculate the costs of products to improve the product mix based on costs and determine the pricing strategies [38]. By connecting corporate strategies with the decision-making of the operating management, managers can make full use of the valuable activities of their companies. With regard to the activities that cannot fulfill the goals of enterprises, reforms or changes can be made. Rectifications can be immediately performed when the project is found to deviate from the original plan to ensure the accomplishment of investment plans. ABC can effectively trace each activity of the costs and then categorize the costs to corresponding products 
according to the causes of the activities so as to provide a reasonable sharing method and improve the production performance measuring method. Particularly, when an enterprise has complicated categories of products or processes, $\mathrm{ABC}$ can provide assistance with managers to learn the resource consumption of different products and processes and offer better cost management [16].

In this paper, the activities of $A B C$ model were classified into green quality-related activities and green quality-unrelated activities. A COQ activity center was created for green quality-related activities. Within the COQ activity center, four nested activity centers were established, i.e., prevention, appraisal, internal failure, and external failure activity centers [9]. For the purpose of improvement, regardless of being green quality-related or quality-unrelated activities, all activities should be identified as VA or NVA activities, as shown in Figure 2.

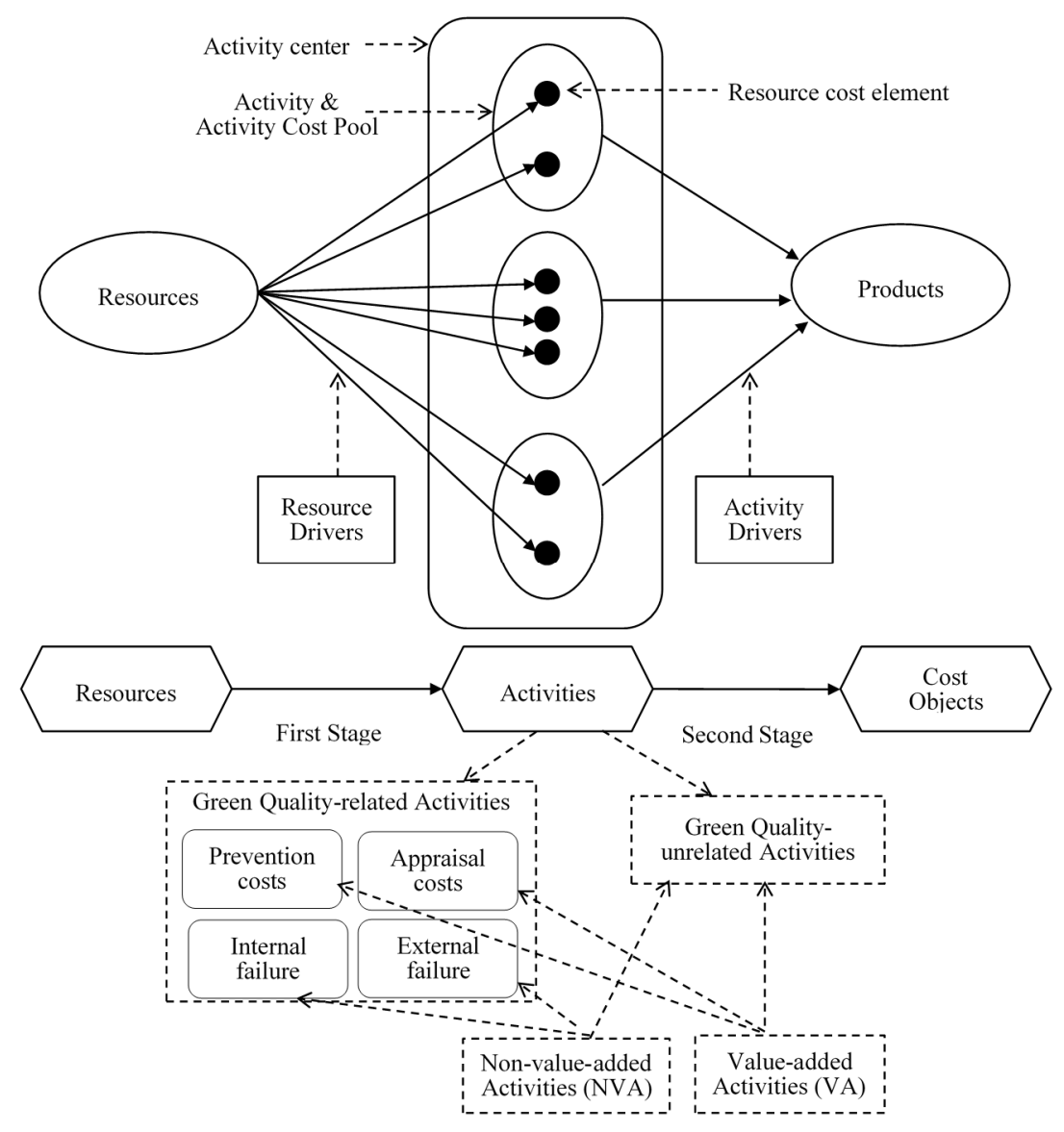

Figure 2. Cost Assignment of ABC's two-stage model.

\subsection{Carbon Tax Functions}

The objective of a carbon tax is to reduce the harmful and unfavorable levels of carbon dioxide emissions, thereby decelerating climate change and its negative effects on the environment and human health [39]. A carbon tax imposes a tax on each unit of carbon emissions and gives companies an incentive to reduce pollution whenever doing so will cost less than paying the tax [40]. In the literature, "carbon tax" [12,13,15,17,41] and "emission tax" [42-44] are used interchangeably, although some argue that a carbon tax simply puts a price on carbon dioxide emissions while an emissions tax puts a price on all pollution emissions, not just carbon dioxide, including methane, carbon monoxide, nitrous oxide, or fluorinated gases, etc. [45]. Some authors use "carbon emission tax" [46-48]. However, most authors mean to levy on all pollution emissions which are converted to a carbon equivalent [49]. This paper also adopted the concept of all pollution emissions and the carbon equivalent. 
This study intended to explore the effects of carbon tax levies on production mix decisions. Figure 3 is the carbon tax function with a fixed tax rate, which has been adopted by many countries presently. However, if the carbon tax level is too low, companies may want to pay the tax and continue to pollute. Thus, the government may use carbon tax functions that have a full progressive tax rate without a threshold (Figure 4) [50] or with a threshold (Figure 5). In these two carbon tax functions, the higher a company's carbon emission quantity, the higher the carbon tax rate. It will have aggressive effect on carbon emission reduction. However, considering small companies with very low levels of production and high levels of carbon pollution, the government may use the carbon tax system with a threshold, as shown in Figure 5, where a company will have a carbon tax exemption when its carbon emission quantity is under threshold quantity [51]. In this paper, a carbon tax system with progressive tax rates and a threshold was used for illustration. On the other hand, the government should help companies reduce carbon emissions by providing subsidies for carbon emission control equipment or other methods. A carbon tax can be a regressive tax, in that it may directly or indirectly affect low-income groups disproportionately [41]. The latter allows for different rates at different carbon levels and can still create a meaningful impact in carbon reduction [52].

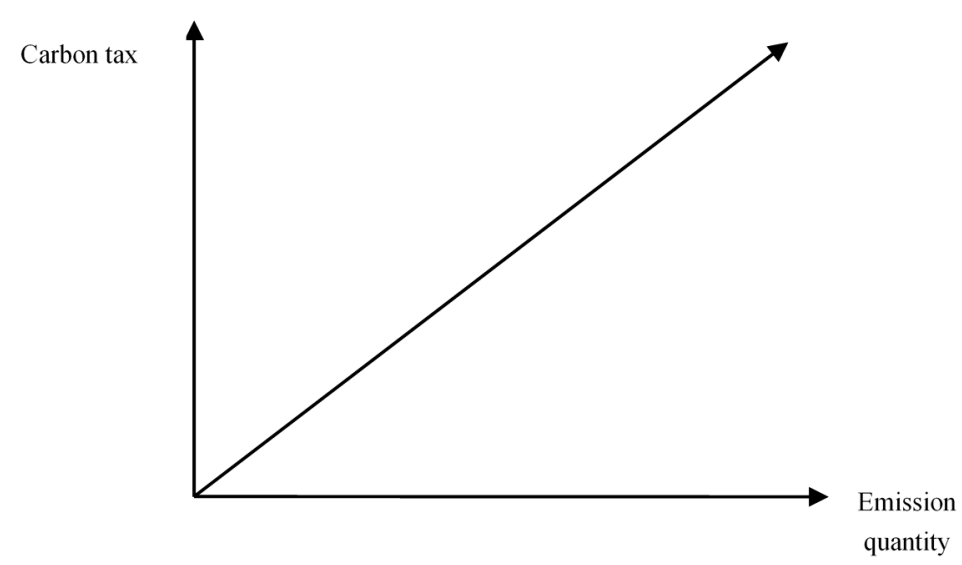

Figure 3. The fixed tax rate.

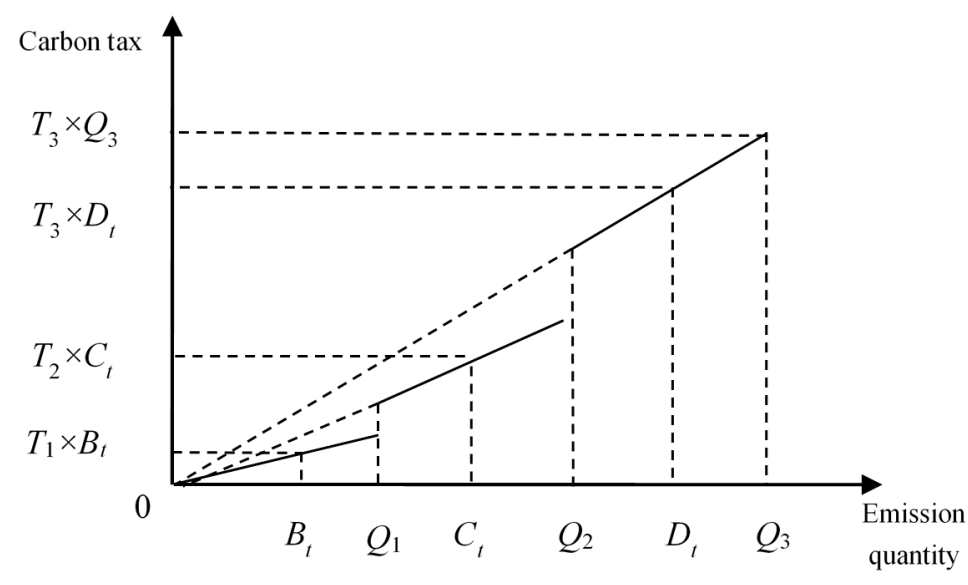

Figure 4. The full progressive tax rate without a threshold. 


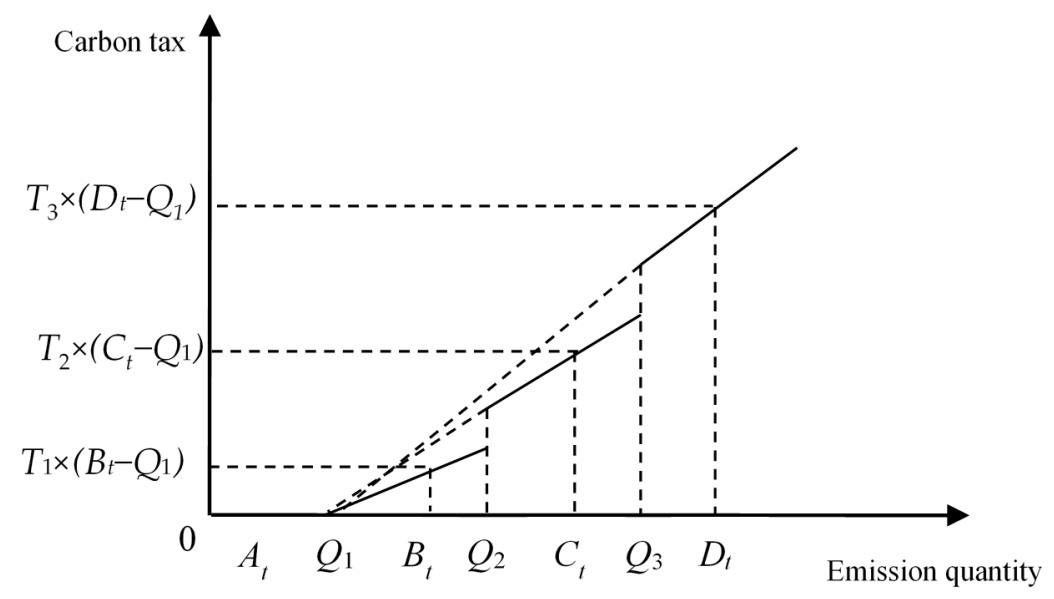

Figure 5. The full progressive tax rate with a threshold.

\section{Model Formulation}

\subsection{Assumptions}

The green quality management decision model under $\mathrm{ABC}$ presented in this paper had several assumptions. First, assume that a multi-product company had various levels of activities including unit-level, batch-level, product-level, and facility-level activities. The company had determined the resource drivers and activity drivers used in $\mathrm{ABC}$ analysis. Second, the company also had calculated the unit cost of each activity based on the actual running activity cost per activity driver and used in the model. Third, the facility-level activity cost was a common fixed cost. Fourth, direct labor resources can be expanded by using additional shifts or overtime work with higher wage rates. Fifth, machine hour resources also can be expanded by renting more machines. Sixth, the products' selling prices were constant within the relevant range of the analysis.

\subsection{Green Quality Management Decision Model under ABC}

According to the assumptions described above, this paper presented a general model that incorporated material purchase discounts, capacity expansions, capacity constraints, waste disposal, and carbon tax expenditures to determine an optimal product-mix decision.

\subsubsection{Notations}

The following notations were used in this paper:

$\pi$ : The company's maximized profit

$p_{i}$ : The unit selling price of product $i$

$q_{i}$ : The production quantity of product $i$

$L_{r}$ : The unit cost of the $r$ th material, without a purchase discount

$L d_{r}$ : The unit cost of the $r$ th material, with the first purchase discount rate

$L d d_{r}$ : The unit cost of the $r$ th material, with the second purchase discount rate

$M_{r}$ : The quantity of the $r$ th material, without a purchase discount

$M d_{r}$ : The quantity of the $r$ th material, with the first purchase discount rate

$M d d_{r}$ : The quantity of the $r$ th material, with the second purchase discount rate

$d_{i r}$ : The requirement of the $r$ th material for product $i$

$X_{r}$ : The upper limit of the $r$ th material quantity with the second purchase discount rate; it is also the available quantity of the $r$ th material

$W_{r}$ : The upper limit of the $r$ th material quantity with the first purchase discount rate

$T D_{r}$ : The upper limit of the $r$ th material quantity without a purchase discount 
$N D_{r}$ : a $0-1$ variable. $N D_{r}=1$ means that the purchase quantity of the $r$ th material falls within the first range of the $r$ th material purchase quantity which dissatisfies the threshold for a discount; otherwise, $N D_{r}=0$

$S D_{r}$ : a $0-1$ variable. $S D_{r}=1$ means that the purchase quantity of the $r$ th material falls within the second range of the $r$ th material purchase quantity which will have the first purchase discount rate; otherwise, $S D_{r}=0$

$O D_{r}$ : a $0-1$ variable. $O D_{r}=1$ means that the quantity of the $r$ th material falls within the third range of the $r$ th material purchase quantity which will have the second purchase discount rate; otherwise, $O D_{r}=0$

$W C_{1}$ : Total direct labor cost when labor hour is below the total normal labor hour, $W_{1}$

$W C_{2}$ : Total direct labor cost in $\mathrm{WH}_{2}$

$W_{3}$ : Total direct labor cost in $\mathrm{WH}_{3}$

TWH: Total direct labor hour

$\mathrm{WH}_{1}$ : The available normal direct labor hour

$\mathrm{WH}_{2}$ : The upper limit of labor hour with the first overtime wage rate

$\mathrm{WH}_{3}$ : The upper limit of labor hour with the second overtime wage rate

$\left(\eta_{1}, \eta_{2}\right)$ : An SOS1 (special ordered set of type 1 ) set of $0-1$ variables, within which exactly one variable must be non-zero

$\left(\alpha_{0}, \alpha_{1}, \alpha_{2}\right)$ : An SOS2 (special ordered set of type 2$)$ set of non-negative variables, within which at most two adjacent variables, in the order given to the set, can be non-zero

$t_{o i}$ : Time of rework mix processing of product $i$

$t_{c i}$ : Time to shift each batch of product $i$ to rework mix department

$t_{\delta i}$ : Time to maintain building tires

$t_{\tau i}$ : Time for the inspection of product $i$

$B A_{i}$ : Batches of product $i$ in rework mix processing

$\delta_{i}$ : Batches of product $i$ in maintenance

$s_{i}$ : Quantity of each maintenance of product $i$

$R_{i}$ : Demand of product $i$

$\tau_{i}: 0-1$ variable. If product $i$ is not produced, it is 0 ; otherwise, it is 1

$\sigma_{o}$ : Capacity of rework mix processing department

$\sigma_{\delta}$ : Capacity of maintenance department

$\sigma_{\tau}$ : Capacity of inspection department

$W A_{1}$ : Total waste disposal cost in $W Q_{1}$

$W A_{2}$ : Total waste disposal cost in $W Q_{2}$

$W A_{3}$ : Total waste disposal cost in $W Q_{3}$

$w_{i}$ : The average waste disposal quantity for one unit of product $i$

$W A Q:$ The total quantity of waste disposal; $W A Q=\sum_{i=1}^{n} w_{i} q_{i}$

$W Q_{1}$ : The upper limit of waste disposal quantity with the first waste disposal cost rate

$W Q_{2}$ : The upper limit of waste disposal quantity with the second waste disposal cost rate

$W Q_{3}$ : The upper limit of waste disposal quantity with the third waste disposal cost rate

$\left(\mu_{1}, \mu_{2}, \mu_{3}\right)$ : An SOS1 (special ordered set of type 1) set of $0-1$ variables, within which exactly one variable must be non-zero

$\left(\beta_{0}, \beta_{1}, \beta_{2}, \beta_{3}\right)$ : An SOS2 (special ordered set of type 2$)$ set of non-negative variables, within which at most two adjacent variables, in the order given to the set, can be non-zero.

$T A_{i}$ : The carbon emission quantity per unit of product $i$

TCQ: The company's total carbon emission quantity; TCQ $=\sum_{i=1}^{n} T A_{i} q_{i}$

$T_{1}$ : The carbon tax rate when TCQ falls within the first taxable range of carbon emission quantity

$T_{2}$ : The carbon tax rate when TCQ falls within the second taxable range of carbon emission quantity

$T_{3}$ : The carbon tax rate when TCQ falls within the third taxable range of carbon emission quantity 
$A_{t}$ : The company's total carbon emission quantity when TCQ falls within the range of carbon emission quantity without carbon tax

$B_{t}$ : The company's total carbon emission quantity when TCQ falls within the first taxable range of carbon emission quantity

$C_{t}$ : The company's total carbon emission quantity when TCQ falls within the second taxable range of carbon emission quantity

$D_{t}$ : The company's total carbon emission quantity when TCQ falls within the third taxable range of carbon emission quantity

$Q_{1}$ : The upper limit of carbon emission quantity without carbon tax

$Q_{2}$ : The upper limit of carbon emission quantity with the first carbon tax rate

$Q_{3}$ : The upper limit of carbon emission quantity with the second carbon tax rate

$G_{1}: 0-1$ variable. $G_{1}=1$ means that TCQ falls within the range of carbon emission quantity without carbon tax; otherwise, $G_{1}=0$

$G_{2}: 0-1$ variable. $G_{2}=1$ means that TCQ falls within the first taxable range of carbon emission quantity; otherwise, $G_{2}=0$

$G_{3}: 0-1$ variable. $G_{3}=1$ means that $T C Q$ falls within the second taxable range of carbon emission quantity; otherwise, $G_{3}=0$

$G_{4}: 0-1$ variable. $G_{4}=1$ means that $T C Q$ falls within the third taxable range of carbon emission quantity; otherwise, $G_{4}=0$

$\left(G_{1}, G_{2}, G_{3}, G_{4}\right)$ : An SOS1 set of $0-1$ variables, within which exactly one variable must be one, which is a set of $0-1$ indicator variables

$H_{i}$ The carbon emission quantity for one unit of product $i$

$M C_{k}$ : Total machine cost when the machine hour is expanded to $k$ th level of machine resource, $M A_{K}$

$M A_{K}$ : The machine hour when the machine hour is expanded to $k$ th level of machine resource

$\left(\theta_{i 1}, \theta_{i 2}, \ldots, \theta_{i k}\right):$ An SOS1 set of $0-1$ variables, within which exactly one variable must be one, which is a set of $0-1$ variables indicating which level of machine hours the machine hour resource is expended to.

\subsubsection{The Objective Function}

The objective of the model is to maximize the total profit of the company, as shown in Equation (1):

$$
\begin{aligned}
M A X \pi= & \sum_{i=1}^{n} p_{i} q_{i}-\sum_{r=1}^{s}\left(L_{r} M_{r}+L d_{r} M d_{r}+L d d_{r} M d d_{r}\right)-\left[W C_{1}+\left(W C_{2}-W C_{1}\right) \alpha_{1}+\left(W C_{3}-W C_{1}\right) \alpha_{2}\right] \\
& -\sum_{i=1}^{n}\left(t_{o i}+t_{c i}\right) k_{o} B A_{i}-\sum_{i=1}^{n}\left(t_{\delta i} \delta_{i}+t_{p i} q_{i}\right) k_{\delta}-\sum_{i=1}^{n}\left(t_{\tau i} k_{\tau} \tau_{i}\right)-\left(W A_{1} \beta_{1}+W A_{2} \beta_{2}+W A_{3} \beta_{3}\right) \\
& -\left[T_{1}\left(B_{t}-Q_{1}\right)+T_{2}\left(C_{t}-Q_{1}\right)+T_{3}\left(D_{t}-Q_{1}\right)\right]-\sum_{k=0}^{t} M C_{k} \theta_{k}-F C
\end{aligned}
$$

$M A X \pi=$ Total revenue - Direct material cost - Direct labor cost - Rework cost - Maintenance cost - Inspection cost - Waste disposal cost - Carbon tax - Machine cost - Other fixed cost, where $\sum_{i=1}^{n} p_{i} q_{i}$ is the total revenue, $\sum_{r=1}^{s}\left(L_{r} M_{r}+L d_{r} M d_{r}+L d d_{r} M d d_{r}\right)$ is the total direct material cost, $\left[W C_{1}+\left(W C_{2}-W C_{1}\right) \alpha_{1}+\left(W C_{3}-W C_{1}\right) \alpha_{2}\right]$ is the total direct labor cost, $\sum_{i=1}^{n}\left(t_{o i}+t_{c i}\right) k_{o} o_{i}$ is the total rework cost, $\sum_{i=1}^{n}\left(t_{\delta i} \delta_{i}+t_{p i} q_{i}\right) k_{\delta}$ is the total maintenance cost, $\sum_{i=1}^{n}\left(t_{\tau i} k_{\tau} \tau_{i}\right)$ is the total inspection cost, $\left(W A_{1} \beta_{1}+W A_{2} \beta_{2}+W A_{3} \beta_{3}\right)$ is the waste disposal cost, $\left[T_{1}\left(B_{t}-Q_{1}\right)+T_{2}\left(C_{t}-Q_{1}\right)+T_{3}\left(D_{t}-Q_{1}\right)\right]$ is the total carbon tax, $\sum_{k=0}^{t} M C_{k} \theta_{k}$ is the total machine cost, and $F C$ is the total other fixed cost. These costs and their associated constraints are described in the following sub-sections. 


\subsubsection{Total Direct Material Cost}

According to the assumption for attaining a discount on the purchase of material, the term $\sum_{r=1}^{s}\left(L_{r} M_{r}+L d_{r} M d_{r}+L d d_{r} M d d_{r}\right)$ in Equation (1) represent the total direct material costs with $(r \in D)$ and without $(r \in D)$ a purchase discount. The material cost function with a purchase quantity discount is shown in Figure 6 [53-56]. There are three ranges of material purchase quantities, $\left[0, T D_{r}\right]$, $\left(T D_{r}, W_{r}\right]$, and $\left(W_{r}, X_{r}\right]$, in which the unit costs are $L_{r}, L d_{r}$, and $L d d_{r}$, respectively, and $L_{r}<L d_{r}<L d d_{r}$. The constraints associated with the material cost are shown in Equations (2)-(10).

Direct material quantity constraints:

$$
\begin{gathered}
\sum_{i=1}^{n} d_{i r} q_{i} \leq X_{r} ; r=1,2, \ldots, s ; r \notin D \\
\sum_{i=1}^{n} d_{i r} q_{i} \leq M_{r}+M d_{r}+M d d_{r} ; r=1,2, \ldots, s ; r \in D \\
M_{r} \geq 0 ; r=1,2, \ldots, s \\
M_{r} \leq T D_{r} N D_{r} ; r=1,2, \ldots, s ; r \in D \\
M d_{r} \geq T D_{r} S D_{r} ; r=1,2, \ldots, s ; r \in D \\
M d_{r} \leq W_{r} S D_{r} ; r=1,2, \ldots, s ; r \in D \\
M d d_{r} \geq W_{r} O D_{r} ; r=1,2, \ldots, s ; r \in D \\
M d d_{r} \leq X_{r} O D_{r} ; r=1,2, \ldots, s ; r \in D \\
N D_{r}+S D_{r}+O D_{r}=1 ; r=1,2, \ldots, s ; r \in D
\end{gathered}
$$

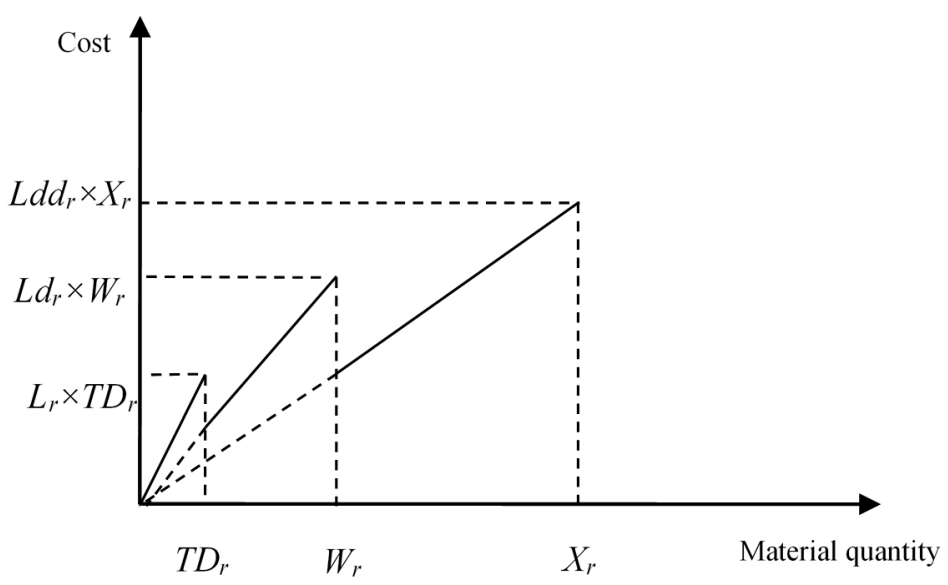

Figure 6. Direct material cost.

Equation (2) is the direct material quantity constraint for materials without a purchase discount $(r \in D)$. Equations (3)-(10) are the constraints for the materials with a purchase $\operatorname{discount}(r \in D) . M_{r}$, $M D_{r}$, and $M d d_{r}$ represent the variables of the material purchase quantity in the three ranges of Figure 5. In addition, $N D_{r}+S D_{r}+O D_{r}=1$, and $N D_{r}, S D_{r}, O D_{r}$ are $0-1$ indicator variables which are used to indicate which range the material purchase quantity is in for the optimal solution. For example, if $N D_{r}=1$, then $S D_{r}=O D_{r}=0$ from Equation (10), which indicates the material purchase quantity is in first range of Figure 5. Then, $0 \leq M_{r} \leq T D_{r}$ from Equations (4) and (5), $M d_{r}=M d d_{r}=0$ from Equations (6)-(9), and $\sum_{i=1}^{n} d_{i r} q_{i} \leq M_{r}$ from Equation (3). Therefore, the total material cost is $L_{r} M_{r}$ for the material with a purchase discount. 


\subsubsection{Total Direct Labor Cost}

In Equation (1) $W C_{1}+\left(W C_{2}-W C_{1}\right) \alpha_{1}+\left(W C_{3}-W C_{1}\right) \alpha_{2}$ represents the total direct labor costs. It is assumed that the direct labor cost for production can be expanded using overtime work, additional night shifts and the hiring of temporary workers as shown in Figure 7. In Figure 7, the available normal direct labor hour is $W H_{1}$, with the fixed cost $W C_{1}$ used no matter how many labor hours the company uses. The labor resources can be expanded to $\mathrm{WH}_{2}$ and $\mathrm{WH}_{3}$ with two different higher wage rates. The total additional labor costs are represented by $\left(W C_{2}-W C_{1}\right) \alpha_{1}+\left(W C_{3}-W C_{1}\right) \alpha_{2}$, and the associated constraints are shown in Equations (11)-(16).

Direct labor hour constraints:

$$
\begin{gathered}
\text { TWH } \leq W H_{1}+\left(W H_{2}-W H_{1}\right) \alpha_{1}+\left(W H_{3}-W H_{1}\right) \alpha_{2} \\
\alpha_{0}-\eta_{1} \leq 0 \\
\alpha_{1}-\eta_{1}-\eta_{2} \leq 0 \\
\alpha_{2}-\eta_{2} \leq 0 \\
\alpha_{0}+\alpha_{1}+\alpha_{2}=1 \\
\eta_{1}+\eta_{2}=1
\end{gathered}
$$

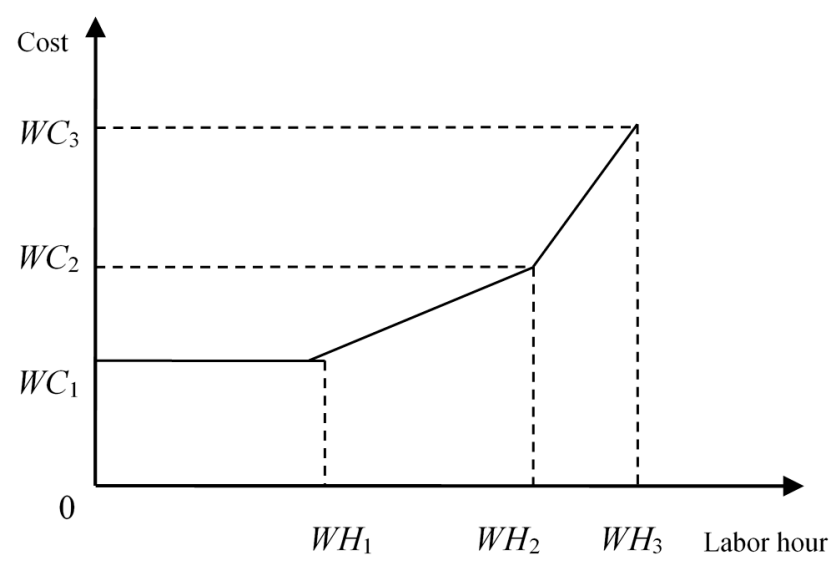

Figure 7. Direct labor cost.

In Equations (11)-(16), $\left(\eta_{1}, \eta_{2}\right)$ is an SOS1 set of $0-1$ variables, within which exactly one variable must be one; $\left(\alpha_{0}, \alpha_{1}, \alpha_{2}\right)$ is an SOS2 set of non-negative variables, within which at most two adjacent variables in the order can be non-zero.

For example, if $\eta_{1}=1$, then $\eta_{2}=0$ from Equation (16), $\alpha_{0} \leq 1, \alpha_{1} \leq 1, \alpha_{2}=0$ from Equations (12)-(14), and $\alpha_{0}+\alpha_{1}=1$ from Equation (15). Thus, the total labor hours (TWH) needed is $W H_{1}+\left(W H_{2}-W H_{1}\right) \alpha_{1}$, and the total labor cost is $T W C=W C_{1}+\left(W C_{2}-W C_{1}\right) \alpha_{1}$. This means that the production will require overtime work in the first overtime work range of Figure 7 , and the final $(T W H, T W C)$ will fall within the second segment of Figure 7 , where $(T W H, T W C)$ is the linear combination of $\left(W H_{1}, W C_{1}\right)$ and $\left(W H_{2}, W C_{2}\right)$. In addition, if $\eta_{2}=1$, then $\eta_{1}=0$ from Equation (16), $\alpha_{0}=0, \alpha_{1} \leq 1, \alpha_{2} \leq 1$ from Equations (12)-(14), and $\alpha_{1}+\alpha_{2}=1$ from Equation (15). Thus, the total labor hour needed is $W H_{1}+\left(W H_{2}-W H_{1}\right) \alpha_{1}+\left(W H_{3}-W H_{1}\right) \alpha_{2}$ and total labor cost is $W C_{1}+\left(W C_{2}-W C_{1}\right) \alpha_{1}+\left(W C_{3}-W C_{1}\right) \alpha_{2}$. This indicates that the production will require overtime work in the second overtime work range of Figure 7, and the final (TWH,TWC) will fall within the second segment of Figure 6, where $(T W H, T W C)$ is the linear combination of $\left(W H_{2}, W C_{2}\right)$ and 
( $\left.W H_{3}, W C_{3}\right)$. When $\eta_{2}=1$ and $\alpha_{0}=1$, then $\eta_{1}=\alpha_{1}=\alpha_{2}=0$ from Equations (12)-(16), the total direct labor hours is $T W H \leq W H_{1}$ from Equation (11) and the total labor cost is the fixed cost $W C_{1}$.

\subsubsection{Total Rework Cost}

In Equation (1), $\sum_{i=1}^{n}\left(t_{o i}+t_{c i}\right) k_{o} B A_{i}$ represents the total rework mix processing costs, and the associated constraints are shown in Equation (17). $t_{o i}$ is the time of rework mix processing and $t_{c i}$ is the time to shift each batch of product $i$ to the rework mix department [57-59]. After mixing, the rubber charge is dropped into a chute and fed by an extruding screw into a roller die. Alternatively, the batch can be dropped onto an open rubber mill system. $k_{0}$ is the unit labor/hour cost of the rework mix processing department. Rework mix processing refers to applying mechanical work to the ingredients in order to blend them into a homogeneous substance. $B A_{i}$ is the batches of rework mix processing and $\sigma_{o}$ is the rework mix processing department production capacity.

Rework constraints:

$$
\sum_{i=1}^{n}\left(t_{o i} B A_{i}+t_{c i} B A_{i}\right) \leq \sigma_{o} ; i=1,2, \ldots, n
$$

\subsubsection{Total Maintenance Cost}

In Equation (1), $\sum_{i=1}^{n}\left(t_{\delta i} \delta_{i}+t_{p i} q_{i}\right) k_{\delta}$ represents the tire building maintenance costs, and the associated constraints are shown in Equations (18) and (19). $t_{\delta i}$ is the time to maintain building tires, $t_{p i}$ is the time to package tires, $k_{\delta}$ is the unit labor/hour costs of the maintenance tire building department, $\delta_{i}$ is the amount of maintenance, and $s_{i}$ is the quantity of each maintenance activity. Equation (18) is the constraint concerning the product quantity and Equation (19) is the constraint concerning the capacity of the maintenance department.

Maintenance constraints:

$$
\begin{gathered}
q_{i}=s_{i} \delta_{i} ; i=1,2, \ldots, n \\
\sum_{i=1}^{n}\left(t_{\delta i} \delta_{i}+t_{p i} q_{i}\right) \leq \sigma_{\delta} ; i=1,2, \ldots, n
\end{gathered}
$$

\subsubsection{Total Inspection Cost}

After the tire has been cured, large commercial truck/bus tires, as well as some passenger and light truck tires, are inspected by $\mathrm{X}$-ray or magnetic induction based inspection machines. Tire balance measurement is a test where the tire is automatically placed on wheel halves, rotated at a high speed, and measured for imbalance. In Equation (1), $\sum_{i=1}^{n}\left(t_{\tau i} k_{\tau} \tau_{i}\right)$ represents the tire inspection cost, and the associated constraints are shown in Equations (20) and (21). $k_{\tau}$ is the unit tire inspection hourly $\operatorname{cost}, t_{\tau i}$ is the inspection time for product $i$, and $\sigma_{\tau}$ is the tire inspection capacity. Equation (20) is the constraint for tire inspection hour capacity, and Equation (21) is the constraint for product demand. $\tau_{i}$ is a $0-1$ variable, in other words, if a tire is not produced, then $\tau_{i}=0$ will result in $q_{i}=0$ from Equation (21); conversely, if it is produced, then $\tau_{i}=1$ will result in $0 \leq q_{i} \leq R_{i}$ from Equation (21).

Inspection constraints:

$$
\begin{aligned}
& \sum_{i=1}^{n}\left(t_{\tau i} \tau_{i}\right) \leq \sigma_{\tau} ; i=1,2, \ldots, n \\
& 0 \leq q_{i} \leq R_{i} \tau_{i} ; i=1,2, \ldots, n
\end{aligned}
$$

\subsubsection{Total Waste Disposal Cost}

The term $\left(W A_{1} \beta_{1}+W A_{2} \beta_{2}+W A_{3} \beta_{3}\right)$ in Equation (1) represents the total waste disposal cost of tire production. It is assumed that the total waste disposal cost function is shown in Figure 8, which is 
a piecewise linear function composed of three segments with different disposal rates. The constraints associated with the company's total waste disposal quantity (WAQ) are as shown in Equations (22)-(38). In Equation (22), WAQ represents the total waste disposal quantity, and $W A Q=\sum_{i=1}^{n} w_{i} q_{i}$, where $w_{i}$ is the average waste disposal quantity for one unit of product $i$.

In Equations (23)-(28), $\left(\mu_{1}, \mu_{2}, \mu_{3}\right)$ is an SOS1 set of $0-1$ variables, within which exactly one variable must be one; $\left(\beta_{0}, \beta_{1}, \beta_{2}, \beta_{3}\right)$ is an SOS2 set of non-negative variables, within which no more than two adjacent variables to the order in the set are non-zero. $\left(\mu_{1}, \mu_{2}, \mu_{3}\right)$ is a set of indicator variables that indicate which range the company's total waste disposal quantity falls within. If $\mu_{1}=1$, then $\mu_{2}=\mu_{3}=0$ from Equation (28), $\beta_{0} \leq 1, \beta_{1} \leq 1$, and $\beta_{2}=\beta_{3}=0$ from Equations (23)-(26). Thus, the company's total waste disposal quantity falls within the first range, $\left[0, W Q_{1}\right]$, i.e., $W A Q=W Q_{1} \beta_{1}$ from Equation (22), and the total waste disposal cost is $W A_{1} \beta_{1}$. Similarly, If $\mu_{2}=1$, then the company's total waste disposal quantity falls within the second range, $\left[W Q_{1}, W Q_{2}\right]$; If $\mu_{3}=1$, then the company's total waste disposal quantity falls within the third range, $\left[W Q_{2}, W Q_{3}\right]$.



Figure 8. Waste disposal cost.

Waste disposal quantity constraints:

$$
\begin{gathered}
W A Q=\sum_{i=1}^{n} w_{i} q_{i}=W Q_{1} \beta_{1}+W Q_{2} \beta_{2}+W Q_{3} \beta_{3} \\
\beta_{0}-\mu_{1} \leq 0 \\
\beta_{1}-\mu_{1}-\mu_{2} \leq 0 \\
\beta_{2}-\mu_{2}-\mu_{3} \leq 0 \\
\beta_{3}-\mu_{3} \leq 0 \\
\beta_{0}+\beta_{1}+\beta_{2}+\beta_{3}=1 \\
\mu_{1}+\mu_{2}+\mu_{3}=1
\end{gathered}
$$

\subsubsection{Carbon Tax Expenditure}

The terms $\left[T_{1}\left(B_{t}-Q_{1}\right)+T_{2}\left(C_{t}-Q_{1}\right)+T_{3}\left(D_{t}-Q_{1}\right)\right]$ in Equation (1) represent the total carbon tax incurred during tire production. It is assumed that the carbon tax function is shown in Figure 4 (replicated for easy reading), which has the full progressive tax rates with a threshold. The constraints associated with the carbon tax function in Figure 4 are shown in Equations (29)-(37). 
Carbon tax constraints:

$$
\begin{aligned}
T C Q=\sum_{i=1}^{n} T A_{i} q_{i} & =A_{t}+B_{t}+C_{t}+D_{t} \\
A_{t} & \geq 0 \\
A_{t} & \leq G_{1} Q_{1} \\
B_{t} & >G_{2} Q_{1} \\
B_{t} & \leq G_{2} Q_{2} \\
C_{t} & >G_{3} Q_{2} \\
C_{t} & \leq G_{3} Q_{3} \\
D_{t} & >G_{4} Q_{3} \\
G_{1}+G_{2} & +G_{3}+G_{4}=1
\end{aligned}
$$

The tire industry is a high emission industry, and the carbon tax is expected to be efficient in terms of the downscaling of production and reduced emissions. A higher rate is imposed on higher carbon contents, and all carbon content levels are accompanied with corresponding progressive rates. The full progressive tax system reports better results in carbon reductions. In Figure 4, the carbon tax rate $T_{1}<T_{2}<T_{3}$. In Equation (29), the company's total carbon emission quantity is TCQ $=\sum_{i=1}^{n} T A_{i} q_{i}$ where $T A_{i}$ is the carbon emission quantity per unit of product $i$; and $A_{t}, B_{t}, C_{t}, D_{t}$ are the variables of TCQ when it falls within the first, second, third, and fourth range of carbon emission quantity shown in Figure 4, respectively. Also, $B_{t}, C_{t}, D_{t}$ are the variables of TCQ when it falls within the first, second, and third taxable range of carbon emission quantity whose carbon tax rates are $T_{1}, T_{2}$, and $T_{3}$, respectively. In Equation (37), $\left(G_{1}, G_{2}, G_{3}, G_{4}\right)$ is an SOS1 set of $0-1$ variables, within which exactly one variable must be one, which is a set of $0-1$ indicator variables. If $G_{1}=1$, then $G_{2}=G_{3}=G_{4}=0$ from Equation (37), $0 \leq A_{t} \leq G_{1} Q_{1}$ from Equations (30) and (31), and $B_{t}=C_{t}=D_{t}=0$ from Equations (32)-(36). Thus, TCQ falls within the first range of Figure 4, in which the carbon tax is zero. Similarly, TCQ falls within the second, third, or fourth range of carbon emission quantities in Figure 4 when $G_{2}=1, G_{3}=1$, or $G_{4}=1$.

\subsubsection{Total Machine Cost}

As shown in Figure 9, this paper assumes that the machine costs are regarded as fixed costs with stepwise function for various machine hour ranges. The total machine cost is $M C_{0}$ under the current capacity of $M A_{i 0}$ machine hours. If tire production requires an expansion of machine hours to $M A_{i 1}, M A_{i 2}, \ldots$, or $M A_{i k}$, the total machine cost will increase to $M C_{i 1}, M_{i 2}, \ldots$, or $M C_{i k}$, respectively. According to the assumption, the term $\sum_{k=0}^{t} M C_{i k} \theta_{i k}$ in Equation (1) represents the total machine costs, and the associated constraints are shown in Equations (38) and (39). $\left(\theta_{i 1}, \theta_{i 2}, \ldots, \theta_{i k}\right)$ is an SOS1 set of $0-1$ variables, within which exactly one variable must be one, which is a set of $0-1$ indicator variables. If $\theta_{i k}=1$, then the machine hours will be expanded to $M A_{i k} \theta_{i k}$, i.e., $H_{i} q_{i} \leq M A_{k} \theta_{k}$, where $H_{i}$ is the carbon emission quantity for one unit of product $i$. Thus, the machine cost will be $M C_{i k} \theta_{i k}$.

Stepwise machine hour constraints:

$$
\begin{gathered}
H_{i} q_{i} \leq \sum_{k=0}^{t} M A_{i k} \theta_{i k} ; i=1,2, \ldots, n \\
\sum_{k=0}^{t} \theta_{i k}=1 ; i=1,2, \ldots, n
\end{gathered}
$$




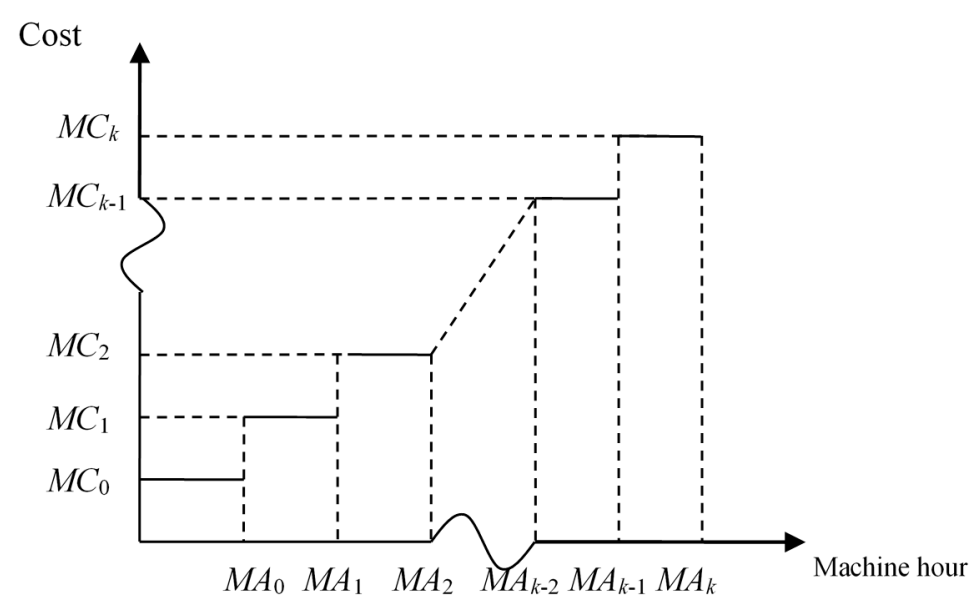

Figure 9. Stepwise process-level activity cost.

\subsubsection{The Complete Model}

The complete green quality management decision model included the objective function, i.e., Equation (1), and Equation (38) constraints associated with various costs, i.e., Equations (2)-(39). This model was used for the analyses of four scenarios for carbon tax and capacity expansion:

- Scenario 1: Current Capacity without Carbon Tax. The complete model for Scenario 1 included the objective function, Equation (1), and 28 constraints, Equations (2)-(28), and Equation (38), in which Equation (38) is $H_{i} q_{i} \leq M A_{i 0}$.

- Scenario 2: Capacity Expansion without Carbon Tax. The complete model for Scenario 2 included the objective function, Equation (1), and Equation (29) constraints, Equations (2)-(28), and Equations (38) and (39).

- Scenario 3: Current Capacity with Carbon Tax. The complete model for Scenario 3 included the objective function, Equation (1), and Equation (37) constraints, Equations (2)-(38), in which Equation (38) is $H_{i} q_{i} \leq M A_{i 0}$.

- Scenario 4: Capacity Expansion with Carbon Tax. The complete model for Scenario 4 included the objective function, Equation (1), and Equation (38) constraints, Equations (2)-(39).

\section{Numerical Illustration}

In this section, a numerical example was used to illustrate the application of the model.

\subsection{Data and Description of a Numerical Example}

In this section, a numerical example in Company $\mathrm{X}$ was used to illustrate the concepts described in the previous section. First, this research obtained the optimal product-mix decision under current capacity status. Then, this research considered the capacity expansion. Finally, this research analyzed the optimal product-mix decision under current capacity and capacity expansion with a carbon tax. It was assumed that Product 1, Product 2 and Product 3 could be sold for NT \$4000, NT \$6000, and NT $\$ 7500$ per unit.

The production process of Company $X$ is shown in Figure 1. Company $X$ needed the following main activities in producing tire products: two unit-level activities, tire building and mixing $(U=\{1,2\})$; two batch-level activities, component preparation and curing $(B=\{3,4\})$; and one product-level activity, product design $(\mathrm{P}=\{5\})$. These activities would need direct material and direct labor hours. Three process-level activities using machine 1, machine 2, and machine 3 were used for product 1 , product 2 , and product 3 , respectively. The company's rework mix processing and extruder control departments were mainly used for rework processing and inspection of each batch of chemicals to 
the mixing department. On average, each rework mix processing took about 15 min for Product 1 , Product 2, and Product 3, and rework mixing natural rubber and chemicals required $50 \mathrm{~min}, 55 \mathrm{~min}$, and $60 \mathrm{~min}$, respectively, to transfer Product 1, Product 2, and Product 3 to the tire building department. It took about $50 \mathrm{~min}$ for each order in the maintenance and pressing department, and it took eight minutes for the pressing of each unit of tires. It required $150 \mathrm{~h}, 300 \mathrm{~h}$, and $250 \mathrm{~h}$ to process each batch of Product 1, Product 2, and Product 3 for inspection, respectively, and the inspection costs were NT $\$ 702,500$. In the second stage of the $\mathrm{ABC}$ cost assignment view, the activity costs were traced to the cost objects. $\mathrm{ABC}$ uses activity drivers to measure the consumption of activities by the cost objects. In this example, products were used as the cost objects. This could trace COQ-related and COQ-unrelated costs to the products, as shown in Table 1.

Table 1. Activity analysis in accordance with COQ and ABC.

\begin{tabular}{cccc}
\hline Activities & Activity Drivers & ABC Categories & COQ Scheme \\
\hline Direct labor & Labor hours & VA & - \\
Machine 1 & Machine hours & VA & - \\
Machine 2 & Machine hours & VA & - \\
Machine 3 & Machine hours & VA & - \\
Marketing, Plant guard \& management & Labor hours & VA & - \\
Waste disposal & Number of disposal & NVA & Internal failure \\
Carbon emission & Carbon emission quantities & NVA & External failure \\
Rework & Labor hours & NVA & Internal failure \\
Inspection & Inspection hours & VA & Appraisal \\
Maintenance & Machine hours & VA & Prevention \\
\hline
\end{tabular}

VA: Value-added; NVA: Non-value-added.

Compounding is the activity of bringing together natural rubber, process oil, carbon black, accelerators, and other additives. The curing press is the activity where tires attain their final shape and tread pattern. Inspection did not just stop at the surface; some tires were sampled from the production line and X-rayed to detect any hidden weaknesses or internal failures. The data of the activity cost for each process and the available capacity are also presented in Table 2. 
Table 2. Data for the numerical example.

\begin{tabular}{|c|c|c|c|c|c|c|c|}
\hline \multicolumn{4}{|c|}{ Panel A: Production Information } & \multirow{2}{*}{$\begin{array}{c}\text { Product } 1 \\
70,000\end{array}$} & \multirow{2}{*}{$\begin{array}{c}\text { Product } 2 \\
40,000\end{array}$} & \multirow{2}{*}{$\begin{array}{c}\text { Product } 3 \\
50,000\end{array}$} & \multirow{2}{*}{$\begin{array}{c}\text { Available Capacity } \\
-\end{array}$} \\
\hline Maximum Demand & & & & & & & \\
\hline Selling Price & & & & $\$ 4000$ & $\$ 6000$ & $\$ 7500$ & - \\
\hline Quantity of Batch & & $B A_{i}$ & & 10 & 4 & 4 & - \\
\hline Quantity of Maintenance & & $s_{i}$ & & 5 & 2 & 2 & - \\
\hline \multicolumn{8}{|l|}{ Direct Material Constraint } \\
\hline \multirow{2}{*}{ Cost/Unit } & $L_{1}=\$ 50 /$ unit & $L d_{1}=\$ 40 /$ unit & $L d d_{1}=\$ 30 /$ unit & 6 & 8 & 10 & $X_{1}=30,000$ \\
\hline & $L_{2}=\$ 40 /$ unit & - & - & 2.5 & 3 & 4 & $X_{2}=10,000$ \\
\hline Material Quantities & $T D_{1}=10,000$ & $W_{1}=20,000$ & - & - & - & - & - \\
\hline \multicolumn{8}{|l|}{ Direct Labour Constraint } \\
\hline Cost & $W C_{1}=\$ 600,000$ & $W C_{2}=\$ 1,100,000$ & $W C_{3}=\$ 2,400,000$ & - & - & - & - \\
\hline Labour Hours & $W H_{1}=3000$ & $\mathrm{WH}_{2}=5000$ & $\mathrm{WH}_{3}=8000$ & 2 & 2 & 3.5 & $W_{3}=8000$ \\
\hline Wage Rate & $W R_{1}=\$ 200 / \mathrm{h}$ & $W R_{2}=\$ 250 / \mathrm{h}$ & $W R_{3}=\$ 300 / \mathrm{h}$ & - & - & - & - \\
\hline \multicolumn{8}{|l|}{ Waste Disposal Constraint } \\
\hline Cost & $W A_{1}=\$ 400,000$ & $W A_{2}=\$ 900,000$ & $W A_{2}=\$ 2,000,000$ & - & - & - & - \\
\hline Disposal Quantity & $W Q_{1}=2000$ & $W Q_{2}=3000$ & $W Q_{3}=5000$ & 2 & 3 & 3 & $W Q_{3}=5000$ \\
\hline Disposal Rate & $D R_{1}=\$ 200 / \mathrm{h}$ & $D R_{2}=\$ 300 / \mathrm{h}$ & $D R_{3}=\$ 400 / \mathrm{h}$ & - & - & - & - \\
\hline \multicolumn{8}{|l|}{ Time Driver } \\
\hline Inspection Hours & & $t_{\tau i}$ & & 150 & 300 & 250 & - \\
\hline Machine Hours & & $H_{i}$ & & 2 & 2 & 3 & \\
\hline \multicolumn{8}{|l|}{ Carbon Emission Constraint } \\
\hline Cost/Unit & $T_{1}=\$ 40 /$ unit & $T_{2}=\$ 50 /$ unit & $T_{3}=\$ 60 /$ unit & - & - & - & - \\
\hline Upper Limit of Carbon Emission Quantity & $Q_{1}=10,000$ & $Q_{2}=12,000$ & $Q_{3}=15,000$ & 20 & 40 & 50 & $Q_{3}=15,000$ \\
\hline \multicolumn{3}{|l|}{ Process-level activity } & Machine 1 & \multicolumn{2}{|c|}{ Machine 2} & \multicolumn{2}{|r|}{ Machine 3} \\
\hline \multicolumn{8}{|l|}{ Current capacity } \\
\hline Cost & & & $M C_{10}=\$ 200,000$ & \multirow{2}{*}{\multicolumn{2}{|c|}{$\begin{array}{c}M C_{20}=\$ 300,000 \\
M A_{20}=3000\end{array}$}} & \multirow{2}{*}{\multicolumn{2}{|c|}{$\begin{array}{c}M C_{30}=\$ 720,000 \\
M A_{30}=6000\end{array}$}} \\
\hline Machine hours & & & $M A_{10}=2000$ & & & & \\
\hline \multicolumn{8}{|l|}{ Capacity expansion 1} \\
\hline Cost & & & $M C_{11}=\$ 450,000$ & \multirow{2}{*}{\multicolumn{2}{|c|}{$\begin{array}{c}M C_{21}=\$ 600,000 \\
M A_{21}=4000\end{array}$}} & \multirow{2}{*}{\multicolumn{2}{|c|}{$\begin{array}{c}M C_{31}=\$ 1,200,000 \\
M A_{31}=8000\end{array}$}} \\
\hline Machine hours & & & $M A_{11}=3000$ & & & & \\
\hline \multicolumn{8}{|l|}{ Capacity expansion 2} \\
\hline Cost & & & $M C_{12}=\$ 1,000,000$ & \multirow{2}{*}{\multicolumn{2}{|c|}{$\begin{array}{c}M C_{22}=\$ 1,200,000 \\
M A_{22}=6000\end{array}$}} & \multirow{2}{*}{\multicolumn{2}{|c|}{$\begin{array}{c}M C_{32}=\$ 1,800,000 \\
M A_{32}=9000\end{array}$}} \\
\hline Machine hours & & & $M A_{12}=5000$ & & & & \\
\hline \multicolumn{8}{|l|}{ Panel B: Resources consumed } \\
\hline \multicolumn{3}{|c|}{ Rework } & \multicolumn{2}{|c|}{ Maintenance } & & Inspe & tion \\
\hline Resources & & 0,000 & $\$ 1,230$, & & & $\$ 702$, & \\
\hline Capacity (hours) & & $=250$ & $\sigma_{\delta}=41$ & & & $\sigma_{\tau}=1$ & \\
\hline Per hour/rate & & $8400 / \mathrm{h}$ & $k_{\delta}=\$ 30$ & & & $k_{\tau}=\$ 70$ & $2.5 / \mathrm{h}$ \\
\hline
\end{tabular}




\subsection{Four Scenario Analyses}

\subsubsection{Scenario 1: Current Capacity without Carbon Tax}

The mathematical programming model for current capacity without carbon tax is shown in Table A1, and the optimal solution is shown in Table 3. The optimal product mix was to produce 580 units, 204 units and 408 units of Product 1, Product 2 and Product 3, respectively. It required 10,000 pounds of rubber and 3694 pounds of chemical materials, and it used $1160 \mathrm{~h}, 408 \mathrm{~h}$ and $1224 \mathrm{~h}$ for Machine 1, Machine 2, and Machine 3, respectively. A total of 2996 units of waste was generated, $250 \mathrm{~h}$ were spent on rework, $700 \mathrm{~h}$ were spent on inspection, and $511 \mathrm{~h}$ were spent on maintenance. For this scenario, the company gained the maximum profit of NT \$2,391,377.

\subsubsection{Scenario 2: Capacity Expansion without Carbon Tax}

The mathematical programming model for capacity expansion without carbon tax is shown in Table A2, and the optimal solution is shown in Table 4. The optimal product mix was to produce 2300 units of Product 1 only. It required 13,800 pounds of rubber and 5750 pounds of chemical materials, and it used $4600 \mathrm{~h}$ for Machine 1. A total of 4600 units of waste was generated, $249 \mathrm{~h}$ were spent on rework, $150 \mathrm{~h}$ were spent on inspection, and $690 \mathrm{~h}$ were spent on maintenance. For this scenario, the company gained the maximum profit of NT $\$ 2,685,958$.

\subsubsection{Scenario 3: Current Capacity with Carbon Tax}

The mathematical programming model for current capacity with carbon tax is shown in Table A3, and the optimal solution is shown in Table 5. The optimal product mix was to produce 1000 units and 284 units of Product 1 and Product 3, respectively. It required 10,000 pounds of rubber and 3636 pounds of chemical materials, and it used $2000 \mathrm{~h}$ and $852 \mathrm{~h}$ for Machine 1 and Machine 3, respectively. A total of 2852 units of waste was generated, $197 \mathrm{~h}$ were spent on rework, $450 \mathrm{~h}$ were spent on inspection, and $456 \mathrm{~h}$ were spent on maintenance. For this scenario, the company gained the maximum profit of NT $\$ 715,867$ and paid a carbon tax of NT $\$ 1,452,000$.

\subsubsection{Scenario 4: Capacity Expansion with Carbon Tax}

The mathematical programming model for capacity expansion with carbon tax is shown in Table A4, and the optimal solution is shown in Table 6. The optimal product mix was to produce 1500 units of Product 1 only. It required 10,000 pounds of rubber and 3750 pounds of chemical materials, and it used $3000 \mathrm{~h}$ for Machine 1. A total of 3000 units of waste was generated, $163 \mathrm{~h}$ were spent on rework, $150 \mathrm{~h}$ were spent on inspection, and $450 \mathrm{~h}$ were spent on maintenance. For this scenario, the company gained the maximum profit of NT $\$ 774,625$ and paid a carbon tax NT $\$ 1,200,000$.

\section{Discussion of Results}

From Scenario 1 to Scenario 3, the production quantity of Product 1 increased from 580 units to 2300 units, and the production quantities of Product 2 and Product 3 decreased to zero. However, the total profit increased from $\$ 2,391,377$ to $\$ 2,695,958$. In Scenario 3, the optimal product mix was to produce 2300 units of Product 1, which was determined by the revenue, resource consumptions, resource expansion costs, the carbon emission quantity of the three products, and the resources available, etc. Considering the scale of economy or satisfying the present customers' need for each product, this study added the constraints of minimum production quantities for products. 
Table 3. Optimal solution for current capacity without carbon tax (Scenario 1).

Optimal Product Mix Solution for Current Capacity without Carbon Tax (Scenario 1)

$q_{1}=580 q_{2}=204 q_{3}=408 M_{r 1}=0 M d_{r 1}=10,000 M d d_{r 1}=0 M_{r 2}=3694 \alpha_{0}=1 \alpha_{1}=0 \alpha_{2}=0 \beta_{0}=0 \beta_{1}=0$

$\beta_{2}=1 \beta_{3}=0 B A_{1}=58 B A_{2}=51 B A_{3}=102 \delta_{1}=116 \delta_{2}=102 \delta_{3}=204 \tau_{1}=1 \tau_{2}=1 \tau_{3}=1 \mathrm{ND}=0 \mathrm{SD}=1 \mathrm{OD}=0$

$\eta_{1}=1 \eta_{2}=0 \mu_{1}=0 \mu_{2}=1 \mu_{3}=0$

The mathematical programming model for current capacity without carbon tax is shown in Table A1.

Table 4. Optimal solution for capacity expansion without carbon tax (Scenario 2).

Optimal Product Mix Solution for Capacity Expansion without Carbon Tax (Scenario 2)

$q_{1}=2300 q_{2}=0 q_{3}=0 M_{r 1}=0 M d_{r 1}=13,800 M d d_{r 1}=0 M_{r 2}=5750 \alpha_{0}=0 \alpha_{1}=1 \alpha_{2}=0 \beta_{0}=0 \beta_{1}=0 \beta_{2}=0 \beta_{3}=1 B A_{1}=230 B A_{2}=0 B A_{3}=0$

$\delta_{1}=460 \delta_{2}=0 \delta_{3}=0 \tau_{1}=1 \tau_{2}=0 \tau_{3}=0 N D=0 S D=1 O D=0 \eta_{1}=0 \eta_{2}=1 \mu_{1}=0 \mu_{2}=0 \mu_{3}=1 \theta_{10}=0 \theta_{11}=0 \theta_{12}=1 \theta_{20}=1 \theta_{21}=0 \theta_{22}=0$

$\theta_{30}=1 \theta_{31}=0 \theta_{32}=0$

The mathematical programming model is shown in Table A2.

Table 5. Optimal solution for current capacity with carbon tax (Scenario 3).

Optimal Product Mix Solution for Current Capacity with Carbon Tax (Scenario 3)

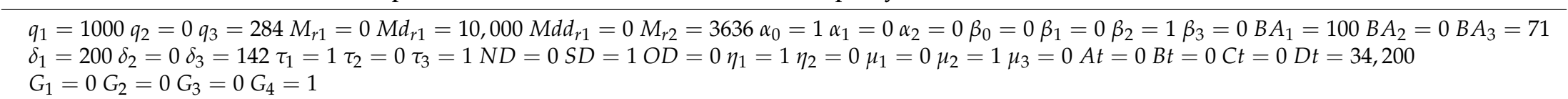

The mathematical programming model for current capacity with carbon tax is shown in Table A3.

Table 6. Optimal solution for capacity expansion with carbon tax (Scenario 4).

\section{Optimal Product Mix Solution for Capacity Expansion with Carbon Tax (Scenario 4)}

$q_{1}=1500 q_{2}=0 q_{3}=0 M_{r 1}=0 M d_{r 1}=10,000 M d d_{r 1}=0 M_{r 2}=3750 \alpha_{0}=1 \alpha_{1}=0 \alpha_{2}=0 \beta_{0}=0 \beta_{1}=0 \beta_{2}=1 \beta_{3}=0 B A_{1}=150 B A_{2}=0 B A_{3}=0$

$\delta_{1}=300 \delta_{2}=0 \delta_{3}=0 \tau_{1}=1 \tau_{2}=0 \tau_{3}=0 N D=0 S D=1 O D=0 \eta_{1}=1 \eta_{2}=0 \mu_{1}=0 \mu_{2}=1 \mu_{3}=0 \theta_{10}=0 \theta_{11}=1 \theta_{12}=0 \theta_{20}=1 \theta_{21}=0 \theta_{22}=0$

$\theta_{30}=1 \theta_{31}=0 \theta_{32}=0 \mathrm{At}=0 \mathrm{Bt}=0 \mathrm{Ct}=0 \mathrm{Dt}=30,000 \mathrm{G}_{1}=0 \mathrm{G}_{2}=0 \mathrm{G}_{3}=0 \mathrm{G}_{4}=1$

The mathematical programming model for capacity expansion with carbon tax is shown in Table A4. 
Similarly, from Scenario 2 to Scenario 4, the production quantity of Product 1 increased from 1000 units to 1500 units, the production quantities of Product 3 decreased to zero, and the total profit increased from $\$ 715,867$ to $\$ 774,625$. The total revenue in the capacity expansion decreased by 130,000 $(6,130,000-6,000,000)$ compared to the original total revenue. Product 1 increased by 500 units, Product 3 decreased by 284 units, and the company's total carbon tax decreased by $252,000(1,452,000-1,200,000)$. The quantity of Product 1 increased but the company's total carbon tax did not increase accordingly, showing that the carbon emission coefficient of Product 1 was lower than that of the other products. This built-in tax flexibility could help firms to minimize their compliance costs over time.

The green quality management (GQM) report, shown in Table 7, included the data of the optimal product-mix, resources consumed, profit, COQ cost, and value-added and non-value-added activity costs for the four scenarios illustrated in this paper. This report provided several considerable advantages to the company. First, with the use of $\mathrm{ABC}$, the activities and associated costs were classified as quality-related or quality-unrelated and VA or NVA in terms of activities. This classification could allow management to detect opportunities for cost reduction and the elimination of NVA activities which could be used in cost management [9]. The applied method was allowed to produce optimally and redirect the productive capacity towards products that save environmental costs and change, modify or redesign the production system from the environmental and quality cost point of view (such as the introduction of low carbon technologies or fuel sources, for example). Second, the measurement and reporting of GQM could provide opportunities which could be used by the organization as long-term performance measurements. Finally, the GQM report presented the cost of each product by activity and quality basis, which could be used to compare the contribution of each product to the company.

Table 7. Green quality management report for comparison of the four decision scenarios.

\begin{tabular}{|c|c|c|c|c|c|}
\hline & & \multicolumn{2}{|c|}{ Current Capacity } & \multicolumn{2}{|c|}{ Capacity Expansion } \\
\hline & & $\begin{array}{c}\text { Without } \\
\text { Carbon Tax } \\
\text { (Scenario 1) }\end{array}$ & $\begin{array}{c}\text { With } \\
\text { Carbon Tax } \\
\text { (Scenario 2) }\end{array}$ & $\begin{array}{c}\text { Without } \\
\text { Carbon Tax } \\
\text { (Scenario 3) }\end{array}$ & $\begin{array}{c}\text { With } \\
\text { Carbon Tax } \\
\text { (Scenario 4) }\end{array}$ \\
\hline \multirow{3}{*}{$\begin{array}{c}\text { Panel A: } \\
\text { Production-mix }\end{array}$} & Product A1 & 580 & 1000 & 2300 & 1500 \\
\hline & Product A2 & 204 & 0 & 0 & 0 \\
\hline & Product A3 & 408 & 284 & 0 & 0 \\
\hline \multirow{11}{*}{$\begin{array}{l}\text { Panel B: } \\
\text { Resources } \\
\text { Consumed }\end{array}$} & Direct material 1 & 10,000 & 10,000 & 13,800 & 10,000 \\
\hline & Direct material 2 & 3694 & 3636 & 5750 & 3750 \\
\hline & Direct labor hours & 2996 & 2994 & 4600 & 3000 \\
\hline & Machine 1 (hours) & 1160 & 2000 & 4600 & 3000 \\
\hline & Machine 2 (hours) & 408 & 0 & 0 & 0 \\
\hline & Machine 3 (hours) & 1224 & 852 & 0 & 0 \\
\hline & Waste disposal & 2996 & 2852 & 4600 & 3000 \\
\hline & Carbon emission & - & 34,200 & - & 30,000 \\
\hline & Rework & 250 & 197 & 249 & 163 \\
\hline & Inspection & 700 & 450 & 150 & 150 \\
\hline & Maintenance & 511 & 456 & 690 & 450 \\
\hline \multirow{14}{*}{ Panel C: Profit } & Revenue & $6,604,000$ & $6,130,000$ & $9,200,000$ & $6,000,000$ \\
\hline & Direct material 1 & 400,000 & 400,000 & 552,000 & 400,000 \\
\hline & Direct material 2 & 147,760 & 145,440 & 230,000 & 150,000 \\
\hline & Direct labor (VA) & 600,000 & 600,000 & $1,100,000$ & 600,000 \\
\hline & Machine 1 (VA) & 200,000 & 200,000 & $1,000,000$ & 450,000 \\
\hline & Machine 2 (VA) & 300,000 & 300,000 & 300,000 & 300,000 \\
\hline & Machine 3 (VA) & 720,000 & 720,000 & 720,000 & 720,000 \\
\hline & Waste disposal cost (NVA, Internal failure) & 900,000 & 900,000 & $2,000,000$ & 900,000 \\
\hline & Carbon tax (NVA, External failure) & - & $1,452,000$ & - & $1,200,000$ \\
\hline & Rework cost (NVA, Internal failure) & 99,933 & 78,833 & 99,667 & 65,000 \\
\hline & Inspection cost (VA, Appraisal) & 491,750 & 281,000 & 105,375 & 105,375 \\
\hline & Maintenance cost (VA, Prevention) & 153,180 & 136,860 & 207,000 & 135,000 \\
\hline & Marketing, Plant guard \& management (VA) & 200,000 & 200,000 & 200,000 & 200,000 \\
\hline & Income based on resources consumed & $2,391,377$ & 715,867 & $2,685,958$ & 774,625 \\
\hline \multirow{5}{*}{$\begin{array}{l}\text { Panel D: COQ } \\
\text { Report }\end{array}$} & Total product cost & $4,012,623$ & $5,214,133$ & $6,314,042$ & $5,025,375$ \\
\hline & Total activity cost & $3,664,863$ & $4,868,693$ & $5,732,042$ & $4,675,375$ \\
\hline & Total VA cost & $2,664,930$ & $2,437,860$ & $3,632,375$ & $2,510,375$ \\
\hline & Total NVA cost & 999,933 & $2,430,833$ & $2,099,667$ & $2,165,000$ \\
\hline & Total COQ cost & $1,644,863$ & $2,848,693$ & $2,412,042$ & $2,405,375$ \\
\hline Data Sources & & Table 3 & Table 5 & Table 4 & Table 6 \\
\hline
\end{tabular}




\section{Conclusions}

Enterprises expand capacity for profit while governments levy carbon emissions and tax standards for environmental protection, and it is necessary to take these two factors into consideration in current enterprise development. As global environmental awareness has become increasingly valued, enterprises also seek environmental protection while at the time gaining profit [9]. In addition to government pressure to reduce environmental pollution, people are forcing the government to formulate strict environmental regulations and levy fines for environmental pollution. In this way, it is hoped that enterprises can reduce pollution via environmental management [29].

Capacity expansion concerns whether an enterprise can achieve sustainable growth, increase sales volume, and even improve enterprise competitiveness. Therefore, how to apply capacity is an important and key factor of enterprises' sustainable activities and ability to maintain competitiveness. The flexible use of capacity strategies to improve competitiveness is also a goal jointly pursued by all enterprises. As a result, how to make good use of capacity to intensify enterprises' competitiveness and advantages is an important issue.

The green quality management decision model proposed in this paper has the following features:

- It uses mathematical programming to simultaneously consider material purchase discounts, capacity expansions, capacity constraints, waste disposal, and carbon tax expenditures in order to determine an optimal product-mix decision.

- It uses Activity-Based Costing to consider various levels of activities in order to accurately measure the cost of activities, identify the costs of quality, and identify the costs of value-added and non-value-added activities, which can indicate the possible benefits of improving or eliminating non-value-added activities.

- It successfully formulates the various cost functions in the mathematical programming, such as material quantity discounts, the labor cost with high overtime rates, the piecewise linear waste disposal cost function, the machine cost with capacity expansion, and the carbon tax with full progressive tax rates and a threshold (used in the illustration). In such a way, companies can incorporate various resource expansions into the mathematical programming model to alleviate the workload of post-optimal analysis.

Additionally, there are two main contributions of this study:

- First, it can provide decision-makers in tire production with the decisions and actions needed to respond to carbon tax policies, and it can provide environmental policy-makers with strategic thinking in policy making.

- Second, it can help enterprises plan new practices for emission reduction and energy saving by combining Activity-based Costing Method and adopting Mathematical Programming Model analysis to create a win-win production method for environmental protection and enterprise profit.

Funding: This research was funded by the Ministry of Science and Technology of Taiwan under Grant No. MOST104-2410-H-008-045 and MOST106-2410-H-008-020-MY3.

Acknowledgments: The author is extremely grateful to the energies journal editorial team and reviewers who provided valuable comments for improving the quality of this article. The author also would like to thank the Ministry of Science and Technology of Taiwan for financial support of this research under Grant No. MOST104-2410-H-008-045 and MOST106-2410-H-008-020-MY3.

Conflicts of Interest: The author declares no conflict of interest. 


\section{Appendix A}

Table A1. The quality management decision model for current capacity without carbon tax (Scenario 1).

\begin{tabular}{|c|c|c|}
\hline $\operatorname{Max} \pi$ & \multicolumn{2}{|c|}{$\begin{array}{l}=4000 \times q_{1}+6000 \times q_{2}+7500 \times q_{3}-50 \times M_{r 1}-40 \times M d_{r 1}-30 \times M d d_{r 1}-40 \times M_{r 2}-600,000-500,000 \times \alpha_{1}-1,800,000 \times \alpha_{2} \\
-15 \times 400 \times\left(B A_{1}+B A_{2}+B A_{3}\right) \div 60-400 \times\left(50 \times B A_{1}+55 \times B A_{2}+60 \times B A_{3}\right) \div 60-300 \times\left(50 \times \delta_{1}+50 \times \delta_{2}+50 \times \delta_{3}\right) \div 60-300 \times\left(8 \times q_{1}+8 \times q_{2}+8 \times q_{3}\right) \div 60 \\
-702.5 \times\left(150 \times \tau_{1}+300 \times \tau_{2}+250 \times \tau_{3}\right)-400,000 \times \beta_{1}-900,000 \times \beta_{2}+200,000 \times \beta_{3}-200,000-300,000-720,000-200,000\end{array}$} \\
\hline & $\begin{array}{c}\text { Subject to-Direct Material } \\
6 \times q_{1}+8 \times q_{2}+10 \times q_{3}-M_{r 1}-M d_{r 1}-M d d_{r 1} \leq 0 \\
2.5 \times q_{1}+3 \times q_{2}+4 \times q_{3}-M_{r 2} \leq 0 \\
N D+S D+O D=1 M_{r 2} \leq 10,000 M_{r 2} \geq 0 \\
M_{r 1} \leq 10,000 \times N D M d_{r 1} \leq 20,000 \times S D M d d_{r 1} \leq 30,000 \times O D \\
M d_{r 1} \geq 10,000 \times S D M d d_{r 1} \geq 20,000 \times O D\end{array}$ & $\begin{array}{c}\text { Subject to-Direct Labour } \\
2 \times q_{1}+2 \times q_{2}+3.5 \times q_{3}-3000-2000 \times \alpha_{1}-5000 \times \alpha_{2} \leq 0 \\
\alpha_{0}-\eta_{1} \leq 0 \alpha_{1}-\eta_{1}-\eta_{2} \leq 0 \alpha_{2}-\eta_{2} \leq 0 \\
\eta_{1}+\eta_{2}=1 \alpha_{0}+\alpha_{1}+\alpha_{2}=1 \\
\text { Subject to-Machine Hour } \\
2 \times q_{1}-2000 \leq 02 \times q_{2}-3000 \leq 03 \times q_{3}-6000 \leq 0\end{array}$ \\
\hline & $\begin{array}{c}\text { Subject to-Inspection } \\
150 \times \tau_{1}+300 \times \tau_{2}+250 \times \tau_{3} \leq 1000 \\
q_{1} \leq 7000 \times \tau_{1} q_{2} \leq 4000 \times \tau_{2} q_{3} \leq 5000 \times \tau_{3} \\
\text { Subject to-Waste Disposal } \\
2 \times q_{1}+3 \times q_{2}+3 \times q_{3}-2000 \beta_{1}-3000 \times \beta_{2}-5000 \times \beta_{3} \leq 0 \\
\beta_{0}-\mu_{1} \leq 0 \beta_{1}-\mu_{1}-\mu_{2} \leq 0 \beta_{2}-\mu_{2}-\mu_{3} \leq 0 \beta_{3}-\mu_{3} \leq 0 \\
\beta_{0}+\beta_{1}+\beta_{2}+\beta_{3}=1 \mu_{1}+\mu_{2}+\mu_{3}=1\end{array}$ & $\begin{array}{c}\text { Subject to-Rework } \\
15 \times B A_{1}+15 \times B A_{2}+15 \times B A_{3}+50 \times B A_{1}+55 \times B A_{2}+60 \times B A_{3} \leq 250 \times 60 \\
q_{1}=B A_{1} \times 10 q_{2}=B A_{2} \times 4 q_{3}=B A_{3} \times 4 \\
\text { Subject to-Maintenance } \\
50 \delta_{1}+50 \delta_{2}+50 \delta_{3}+8 q_{1}+8 q_{2}+8 q_{3} \leq 4100 \times 60 \\
q_{1}=5 \times \delta_{1} q_{2}=2 \times \delta_{2} q_{3}=2 \times \delta_{3}\end{array}$ \\
\hline
\end{tabular}


Table A2. The quality management decision model for capacity expansion without carbon tax (Scenario 2).

\begin{tabular}{|c|c|c|}
\hline $\operatorname{Max} \pi$ & \multicolumn{2}{|c|}{$\begin{array}{l}=4000 \times q_{1}+6000 \times q_{2}+7500 \times q_{3}-50 \times M_{r 1}-40 \times M d_{r 1}-30 \times M d d_{r 1}-40 \times M_{r 2}-600,000-500,000 \times \alpha_{1}-1,800,000 \times \alpha_{2} \\
-15 \times 400 \times\left(B A_{1}+B A_{2}+B A_{3}\right) \div 60-400 \times\left(50 \times B A_{1}+55 \times B A_{2}+60 \times B A_{3}\right) \div 60-300 \times\left(50 \times \delta_{1}+50 \times \delta_{2}+50 \times \delta_{3}\right) \div 60-300 \times\left(8 \times q_{1}+8 \times q_{2}+8 \times q_{3}\right) \div 60 \\
-702.5 \times\left(150 \times \tau_{1}+300 \times \tau_{2}+250 \times \tau_{3}\right)-400,000 \times \beta_{1}-900,000 \times \beta_{2}+200,000 \times \beta_{3} \\
-200,000 \times \theta_{10}-300,000 \times \theta_{20}-720,000 \times \theta_{30}-450,000 \times \theta_{11}-600,000 \times \theta_{21}-1,200,000 \times \theta_{31}-1,000,000 \times \theta_{12}-1,200,000 \times \theta_{22}-1,800,000 \times \theta_{32}-200,000\end{array}$} \\
\hline & $\begin{array}{c}\text { Subject to-Direct Material } \\
6 \times q_{1}+8 \times q_{2}+10 \times q_{3}-M_{r 1}-M d_{r 1}-M d d_{r 1} \leq 0 \\
2.5 \times q_{1}+3 \times q_{2}+4 \times q_{3}-M_{r 2} \leq 0 \\
N D+S D+O D=1 M_{r 2} \leq 10,000 M_{r 2} \geq 0 \\
M_{r 1} \leq 10,000 \times N D M d_{r 1} \leq 20,000 \times S D M d d_{r 1} \leq 30,000 \times O D \\
M d_{r 1} \geq 10,000 \times S D M d d_{r 1} \geq 20,000 \times O D\end{array}$ & $\begin{array}{c}\text { Subject to-Direct Labour } \\
2 \times q_{1}+2 \times q_{2}+3.5 \times q_{3}-3000-2000 \times \alpha_{1}-5000 \times \alpha_{2} \leq 0 \\
\alpha_{0}-\eta_{1} \leq 0 \alpha_{1}-\eta_{1}-\eta_{2} \leq 0 \alpha_{2}-\eta_{2} \leq 0 \\
\eta_{1}+\eta_{2}=1 \alpha_{0}+\alpha_{1}+\alpha_{2}=1 \\
\text { Subject to-Rework } \\
15 \times B A_{1}+15 \times B A_{2}+15 \times B A_{3}+50 \times B A_{1}+55 \times B A_{2}+60 \times B A_{3} \leq 250 \times 60 \\
q_{1}=B A_{1} \times 10 q_{2}=B A_{2} \times 4 q_{3}=B A_{3} \times 4\end{array}$ \\
\hline & $\begin{array}{c}\text { Subject to-Inspection } \\
150 \times \tau_{1}+300 \times \tau_{2}+250 \times \tau_{3} \leq 1000 \\
q_{1} \leq 7000 \times \tau_{1} q_{2} \leq 4000 \times \tau_{2} q_{3} \leq 5000 \times \tau_{3} \\
\text { Subject to-Waste Disposal } \\
2 \times q_{1}+3 \times q_{2}+3 \times q_{3}-2000 \beta_{1}-3000 \times \beta_{2}-5000 \times \beta_{3} \leq 0 \\
\beta_{0}-\mu_{1} \leq 0 \beta_{1}-\mu_{1}-\mu_{2} \leq 0 \beta_{2}-\mu_{2}-\mu_{3} \leq 0 \beta_{3}-\mu_{3} \leq 0 \\
\beta_{0}+\beta_{1}+\beta_{2}+\beta_{3}=1 \mu_{1}+\mu_{2}+\mu_{3}=1 \\
\end{array}$ & $\begin{array}{c}\text { Subject to-Stepwise Machine Hour } \\
2 \times q_{1}-2000 \times \theta_{10}-3000 \times \theta_{11}-5000 \times \theta_{12} \leq 0 \theta_{10}+\theta_{11}+\theta_{12}=1 \\
2 \times q_{2}-3000 \times \theta_{20}-4000 \times \theta_{21}-6000 \times \theta_{22} \leq 0 \theta_{20}+\theta_{21}+\theta_{22}=1 \\
3 \times q_{3}-6000 \times \theta_{30}-8000 \times \theta_{31}-9000 \times \theta_{32} \leq 0 \theta_{30}+\theta_{31}+\theta_{32}=1 \\
\quad \text { Subject to-Maintenance } \\
50 \delta_{1}+50 \delta_{2}+50 \delta_{3}+8 q_{1}+8 q_{2}+8 q_{3} \leq 4100 \times 60 \\
q_{1}=5 \times \delta_{1} q_{2}=2 \times \delta_{2} q_{3}=2 \times \delta_{3} \\
\end{array}$ \\
\hline
\end{tabular}


Table A3. The quality management decision model for current capacity with carbon tax (Scenario 3).

\begin{tabular}{|c|c|c|}
\hline $\operatorname{Max} \pi$ & \multicolumn{2}{|c|}{$\begin{array}{l}=4000 \times q_{1}+6000 \times q_{2}+7500 \times q_{3}-50 \times M_{r 1}-40 \times M d_{r 1}-30 \times M d d_{r 1}-40 \times M_{r 2}-600,000-500,000 \times \alpha_{1}-1,800,000 \times \alpha_{2} \\
-15 \times 400 \times\left(B A_{1}+B A_{2}+B A_{3}\right) \div 60-400 \times\left(50 \times B A_{1}+55 \times B A_{2}+60 \times B A_{3}\right) \div 60-300 \times\left(50 \times \delta_{1}+50 \times \delta_{2}+50 \times \delta_{3}\right) \div 60-300 \times\left(8 \times q_{1}+8 \times q_{2}+8 \times q_{3}\right) \div 60 \\
-702.5 \times\left(150 \times \tau_{1}+300 \times \tau_{2}+250 \times \tau_{3}\right)-400,000 \times \beta_{1}-900,000 \times \beta_{2}+200,000 \times \beta_{3}-40 \times(B t-10,000)-50 \times(C t-10,000)-60 \times(D t-10,000) \\
-200,000-300,000-720,000-200,000\end{array}$} \\
\hline & $\begin{array}{c}\text { Subject to-Direct Material } \\
6 \times q_{1}+8 \times q_{2}+10 \times q_{3}-M_{r 1}-M d_{r 1}-M d d_{r 1} \leq 0 \\
2.5 \times q_{1}+3 \times q_{2}+4 \times q_{3}-M_{r 2} \leq 0 \\
N D+S D+O D=1 M_{r 2} \leq 10,000 M_{r 2} \geq 0 \\
M_{r 1} \leq 10,000 \times N D M d_{r 1} \leq 20,000 \times S D M d d_{r 1} \leq 30,000 \times O D \\
M d_{r 1} \geq 10,000 \times S D M d d_{r 1} \geq 20,000 \times O D\end{array}$ & $\begin{array}{c}\text { Subject to-Direct Labour } \\
2 \times q_{1}+2 \times q_{2}+3.5 \times q_{3}-3000-2000 \times \alpha_{1}-5000 \times \alpha_{2} \leq 0 \\
\alpha_{0}-\eta_{1} \leq 0 \alpha_{1}-\eta_{1}-\eta_{2} \leq 0 \alpha_{2}-\eta_{2} \leq 0 \\
\eta_{1}+\eta_{2}=1 \alpha_{0}+\alpha_{1}+\alpha_{2}=1 \\
\text { Subject to-Machine hour } \\
2 \times q_{1}-2000 \leq 02 \times q_{2}-3000 \leq 03 \times q_{3}-6000 \leq 0\end{array}$ \\
\hline & $\begin{array}{c}\text { Subject to-Waste Disposal } \\
2 \times q_{1}+3 \times q_{2}+3 \times q_{3}-2000 \beta_{1}-3000 \times \beta_{2}-5000 \times \beta_{3} \leq 0 \\
\beta_{0}-\mu_{1} \leq 0 \beta_{1}-\mu_{1}-\mu_{2} \leq 0 \beta_{2}-\mu_{2}-\mu_{3} \leq 0 \beta_{3}-\mu_{3} \leq 0 \\
\beta_{0}+\beta_{1}+\beta_{2}+\beta_{3}=1 \mu_{1}+\mu_{2}+\mu_{3}=1 \\
\text { Subject to-Carbon Tax } \\
20 \times q_{1}+40 \times q_{2}+50 \times q_{3} \leq A t+B t+C t+D t \\
\text { At } \geq 0 A t \leq G_{1} \times 10,000 B t \geq G_{2} \times 10,000 B t \leq G_{2} \times 12,000 \\
C t \geq G_{3} \times 12,000 C t \leq G_{3} \times 15,000 D t \geq G_{4} \times 15,000 \\
G_{1}+G_{2}+G_{3}+G_{4}=1\end{array}$ & $\begin{array}{c}\text { Subject to-Rework } \\
15 \times B A_{1}+15 \times B A_{2}+15 \times B A_{3}+50 \times B A_{1}+55 \times B A_{2}+60 \times B A_{3} \leq 250 \times 60 \\
q_{1}=B A_{1} \times 10 q_{2}=B A_{2} \times 4 q_{3}=B A_{3} \times 4 \\
\text { Subject to-Maintenance } \\
50 \delta_{1}+50 \delta_{2}+50 \delta_{3}+8 q_{1}+8 q_{2}+8 q_{3} \leq 4100 \times 60 \\
q_{1}=5 \times \delta_{1} q_{2}=2 \times \delta_{2} q_{3}=2 \times \delta_{3} \\
\text { Subject to-Inspection } \\
150 \times \tau_{1}+300 \times \tau_{2}+250 \times \tau_{3} \leq 1000 \\
q_{1} \leq 7000 \times \tau_{1} q_{2} \leq 4000 \times \tau_{2} q_{3} \leq 5000 \times \tau_{3}\end{array}$ \\
\hline
\end{tabular}


Table A4. The quality management decision model for capacity expansion with carbon tax (Scenario 4).

\begin{tabular}{|c|c|c|}
\hline $\operatorname{Max} \pi$ & \multicolumn{2}{|c|}{$\begin{array}{l}=4000 \times q_{1}+6000 \times q_{2}+7500 \times q_{3}-50 \times M_{r 1}-40 \times M d_{r 1}-30 \times M d d_{r 1}-40 \times M_{r 2}-600,000-500,000 \times \alpha_{1}-1,800,000 \times \alpha_{2}-15 \times 400 \times\left(B A_{1}+B A_{2}+B A_{3}\right) \div 60 \\
-400 \times\left(50 \times B A_{1}+55 \times B A_{2}+60 \times B A_{3}\right) \div 60-300 \times\left(50 \times \delta_{1}+50 \times \delta_{2}+50 \times \delta_{3}\right) \div 60-300 \times\left(8 \times q_{1}+8 \times q_{2}+8 \times q_{3}\right) \div 60-702.5 \times\left(150 \times \tau_{1}+300 \times \tau_{2}+250 \times \tau_{3}\right) \\
-400,000 \times \beta_{1}-900,000 \times \beta_{2}-200,000 \beta_{3}-40 \times(B t-10,000)-50 \times(C t-10,000)-60 \times(D t-10,000)-200,000 \times \theta_{10}-300,000 \times \theta_{20}-720,000 \times \theta_{30} \\
-450,000 \times \theta_{11}-600,000 \times \theta_{21}-1,200,000 \times \theta_{31}-1,000,000 \times \theta_{12}-1,200,000 \times \theta_{22}-1,800,000 \times \theta_{32}-200,000\end{array}$} \\
\hline & $\begin{array}{c}\text { Subject to-Direct Material } \\
6 \times q_{1}+8 \times q_{2}+10 \times q_{3}-M_{r 1}-M d_{r 1}-M d d_{r 1} \leq 0 \\
2.5 \times q_{1}+3 \times q_{2}+4 \times q_{3}-M_{r 2} \leq 0 \\
N D+S D+O D=1 M_{r 2} \leq 10,000 M_{r 2} \geq 0 \\
M_{r 1} \leq 10,000 \times N D M d_{r 1} \leq 20,000 \times S D M d d_{r 1} \leq 30,000 \times O D \\
M d_{r 1} \geq 10,000 \times S D M d d_{r 1} \geq 20,000 \times O D\end{array}$ & $\begin{array}{c}\text { Subject to-Direct Labour } \\
2 \times q_{1}+2 \times q_{2}+3.5 \times q_{3}-3000-2000 \times \alpha_{1}-5000 \times \alpha_{2} \leq 0 \\
\alpha_{0}-\eta_{1} \leq 0 \alpha_{1}-\eta_{1}-\eta_{2} \leq 0 \alpha_{2}-\eta_{2} \leq 0 \\
\eta_{1}+\eta_{2}=1 \alpha_{0}+\alpha_{1}+\alpha_{2}=1 \\
\text { Subject to-Rework } \\
15 \times B A_{1}+15 \times B A_{2}+15 \times B A_{3}+50 \times B A_{1}+55 \times B A_{2}+60 \times B A_{3} \leq 250 \times 60 \\
q_{1}=B A_{1} \times 10 q_{2}=B A_{2} \times 4 q_{3}=B A_{3} \times 4\end{array}$ \\
\hline & $\begin{array}{c}\text { Subject to-Inspection } \\
150 \times \tau_{1}+300 \times \tau_{2}+250 \times \tau_{3} \leq 1000 \\
q_{1} \leq 7000 \times \tau_{1} q_{2} \leq 4000 \times \tau_{2} q_{3} \leq 5000 \times \tau_{3} \\
\text { Subject to-Waste disposal } \\
2 \times q_{1}+3 \times q_{2}+3 \times q_{3}-2000 \beta_{1}-3000 \times \beta_{2}-5000 \times \beta_{3} \leq 0 \\
\beta_{0}-\mu_{1} \leq 0 \beta_{1}-\mu_{1}-\mu_{2} \leq 0 \beta_{2}-\mu_{2}-\mu_{3} \leq 0 \beta_{3}-\mu_{3} \leq 0 \\
\beta_{0}+\beta_{1}+\beta_{2}+\beta_{3}=1 \mu_{1}+\mu_{2}+\mu_{3}=1 \\
\text { Subject to-Shipping } \\
50 \delta_{1}+50 \delta_{2}+50 \delta_{3}+8 q_{1}+8 q_{2}+8 q_{3} \leq 4100 \times 60 \\
q_{1}=5 \times \delta_{1} q_{2}=2 \times \delta_{2} q_{3}=2 \times \delta_{3}\end{array}$ & $\begin{array}{c}\text { Subject to-Stepwise Machine Hour } \\
\begin{array}{c}2 \times q_{1}-2000 \times \theta_{10}-3000 \times \theta_{11}-5000 \times \theta_{12} \leq 0 \theta_{10}+\theta_{11}+\theta_{12}=1 \\
2 \times q_{2}-3000 \times \theta_{20}-4000 \times \theta_{21}-6000 \times \theta_{22} \leq 0 \theta_{20}+\theta_{21}+\theta_{22}=1 \\
3 \times q_{3}-6000 \times \theta_{30}-8000 \times \theta_{31}-9000 \times \theta_{32} \leq 0 \theta_{30}+\theta_{31}+\theta_{32}=1 \\
\text { Subject to-Carbon Tax } \\
20 \times q_{1}+40 \times q_{2}+50 \times q_{3} \leq A t+B t+C t+D t \\
A t \geq 0 A t \leq G_{1} \times 10,000 B t \geq G_{2} \times 10,000 B t \leq G_{2} \times 12,000 \\
C t \geq G_{3} \times 12,000 C t \leq G_{3} \times 15,000 D t \geq G_{4} \times 15,000 \\
G_{1}+G_{2}+G_{3}+G_{4}=1\end{array}\end{array}$ \\
\hline
\end{tabular}




\section{References}

1. Report of the Conference of the Parties on Its Twenty-First Session. 2015. Available online: http:/ / unfccc. int/resource/docs/2015/cop21/eng/10a01.pdf. (accessed on 11 July 2018).

2. Hunter, D. Implications of the Copenhagen Accord for Global Climate Governance. Sustain. Dev. Law Policy 2010, 10, 4-15, 56-57.

3. Abas, N.; Kalair, A.R.; Khan, N.; Haider, A.; Saleem, Z.; Saleem, M.S. Natural and synthetic refrigerants, global warming: A review. Renew. Sustain. Energy Rev. 2018, 90, 557-569. [CrossRef]

4. Douiri, L.; Jabri, A.; El Barkany, A. Models for optimization of supply chain network design integrating the cost of quality: A literature review. Am. J. Ind. Bus. Manag. 2016, 6, 860-876. [CrossRef]

5. García-Pastor, A.; Guirao, B.; López-Lambas, M.E. Quality cost in bus operations based on activity-based costing. Proc. Inst. Civ. Eng. Transp. 2016, 169, 107-117. [CrossRef]

6. Ittner, C.D. Activity-based costing concepts for quality improvement. Eur. Manag. J. 1999, 17, $492-500$. [CrossRef]

7. Khataie, A.H.; Bulgak, A.A. A cost of quality decision support model for lean manufacturing: Activity-based costing application. Int. J. Qual. Reliab. Manag. 2013, 30, 751-764. [CrossRef]

8. Özkan, S.; Karaibrahimoğlu, Y.Z. Activity-based costing approach in the measurement of cost of quality in SMEs: A case study. Total Qual. Manag. Bus. Excell. 2013, 24, 420-431. [CrossRef]

9. Tsai, W.-H. Quality cost measurement under activity-based costing. Int. J. Qual. Reliab. Manag. 1998, 15, 719-752. [CrossRef]

10. Turney, P.B.B. Common Cents: The ABC Performance Breakthrough—How to Succeed with Activity-Based Costing; McGraw-Hill Education: New York, NY, USA, 2005.

11. Goldratt, E.M.; Cox, J. The Goal: Excellence in Manufacturing; North River Press: Great Barrington, MA, USA, 1984.

12. Yi, Y.; Li, J. Cost-Sharing Contracts for Energy Saving and Emissions Reduction of a Supply Chain under the Conditions of Government Subsidies and a Carbon Tax. Sustainability 2018, 10, 895.

13. Baranzini, A.; Carattini, S. Effectiveness, earmarking and labeling: testing the acceptability of carbon taxes with survey data. Environ. Econ. Policy Stud. 2017, 19, 197-227. [CrossRef]

14. Bhupendra, K.V.; Sangle, S. Pollution Prevention Strategy: A Study of Indian Firms. J. Clean. Prod. 2016, 133, 795-802. [CrossRef]

15. Tsai, W.-H.; Yang, C.-H.; Huang, C.-T.; Wu, Y.-Y. The Impact of the Carbon Tax Policy on Green Building Strategy. J. Environ. Plan. Manag. 2017, 60, 1412-1438. [CrossRef]

16. Tsai, W.-H.; Chang, J.-C.; Hsieh, C.-L.; Tsaur, T.-S.; Wang, C.-W. Sustainability Concept in Decision-Making: Carbon Tax Consideration for Joint Product Mix Decision. Sustainability 2016, 8, 1232. [CrossRef]

17. Revoredo-Giha, C.; Chalmers, N.; Akaichi, F. Simulating the Impact of Carbon Taxes on Greenhouse Gas Emission and Nutrition in the UK. Sustainability 2018, 10, 134. [CrossRef]

18. Chopra, A.; Garg, D. Behavior patterns of quality cost categories. TQM J. 2011, 23, 510-515. [CrossRef]

19. Chopra, S.; Wu, P.-J. Eco-activities and operating performance in the computer and electronics industry. Eur. J. Oper. Res. 2016, 248, 971-981. [CrossRef]

20. Grottke, M.; Schleich, B. Cost Optimality in Testing and Rejuvenation. In Proceedings of the 23rd IEEE International Symposium on Software Reliability Engineering Workshops, Dallas, TX, USA, 27-30 November 2012; pp. 259-264.

21. Tye, L.H.; Halim, H.A.; Ramayah, T. An exploratory study on cost of quality implementation in Malaysia: The case of Penang manufacturing firms. Total Qual. Manag. Bus. Excell. 2011, 22, 1299-1315. [CrossRef]

22. Trongkaew, P.; Utistham, T.; Reubroycharoen, P.; Hinchiranan, N. Photocatalytic Desulfurization of Waste Tire Pyrolysis Oil. Energies 2011, 4, 1880-1896. [CrossRef]

23. Yu, H.; Solvang, W.D. Enhancing the Competitiveness of manufacturers through Small-scale Intelligent Manufacturing System (SIMS): A Supply Chain Perspective. In Proceedings of the 6th International Conference on Industrial Technology and Management (ICITM), Cambridge, UK, 7-10 March 2017. [CrossRef]

24. Blanchet, M.; Rinn, T.; Thaden, G.V.; Thieulloy, G.D. INDUSTRY 4.0 The New Industrial Revolution: How Europe Will Succeed. Available online: http:/ /www.iberglobal.com/files/Roland_Berger_Industry.pdf (accessed on 11 July 2018). 
25. Erol, S.; Schumacher, A.; Sihn, W. Strategic guidance towards Industry 4.0-A three-stage process model. In Proceedings of the International Conference on Competitive Manufacturing, Stellenbosch, South Africa, 27-29 January 2016.

26. Zhong, R.Y.; Xu, X.; Klotz, E.; Newman, S.T. Intelligent Manufacturing in the Context of Industry 4.0: A Review. Engineering 2017, 3, 616-630. [CrossRef]

27. Liu, Y.; Xu, X. Industry 4.0 and cloud manufacturing: A comparative analysis. J. Manuf. Sci. Eng. 2016, 139. [CrossRef]

28. Talkhestani, B.A.; Jazdi, N.; Schlögl, W.; Weyrich, M. A concept in synchronization of virtual production system with real factory based on anchor-point method. Procedia CIRP 2018, 67, 13-17. [CrossRef]

29. Oviroh, P.; Jen, T.-C. The Energy Cost Analysis of Hybrid Systems and Diesel Generators in Powering Selected Base Transceiver Station Locations in Nigeria. Energies 2018, 11, 687. [CrossRef]

30. Wan, J.; Tang, S.; Shu, Z.; Li, D.; Wang, S.; Imran, M.; Vasilakos, A.V. Software-Defined Industrial Internet of Things in the Context of Industry 4.0. IEEE Sensors J. 2016, 16, 7373-7380. [CrossRef]

31. Yang, Y.; Li, X.; Yang, Z.; Wei, Q.; Wang, N.; Wang, L. The Application of Cyber Physical System for Thermal Power Plants: Data-Driven Modeling. Energies 2018, 11, 690. [CrossRef]

32. Paraskevopoulos, D.; Karakitsos, E.; Rustem, B. Robust capacity planning under uncertainty. Manag. Sci. 1991, 37, 787-800. [CrossRef]

33. Aghezzaf, B.; Hachimi, M. Generalized invexity and duality in multiobjective programming problems. J. Glob. Optim. 2000, 18, 91-101. [CrossRef]

34. De Kok, T.G. Capacity allocation and outsourcing in a process industry. Int. J. Prod. Econ. 2000, 68, 229-239. [CrossRef]

35. Kaplan, R.S. Cost and Effect: Using Integrated Cost Systems to Drive Profitability and Performance; Harvard Business School Press: Boston, MA, USA, 1998.

36. Huang, S.-Y.; Chen, H.-J.; Chiu, A.-A.; Chen, C.-P. The application of the theory of constraints and activity-based costing to business excellence: The case of automotive electronics manufacture firms. Total Qual. Manag. Bus. Excell. 2014, 25, 532-545. [CrossRef]

37. Tsai, W.-H.; Hsu, J.-L.; Chen, C.-H.; Chou, Y.-W.; Lin, S.-J.; Lin, W.-R. Application of ABC in hot spring country inn. Int. J. Manag. Enterp. Dev. 2010, 8, 152-174. [CrossRef]

38. Oh, S.-C.; Hildreth, A.J. Decisions on Energy Demand Response Option Contracts in Smart Grids Based on Activity-Based Costing and Stochastic Programming. Energies 2013, 6, 425-443. [CrossRef]

39. Nordhaus, W.D. Carbon taxes to move toward fiscal sustainability. The Economists' Voice 2.0: The Financial Crisis, Health Care Reform, and More; Edlin, A.S., Stiglitz, J.E., Eds.; Columbia University Press: New York, NY, USA, 2012; pp. 208-214.

40. Carbon Tax vs Cap-and-Trade: Which Is Better? Available online: https://www.theguardian.com/ environment/2013/jan/31/carbon-tax-cap-and-trade. (accessed on 11 July 2018).

41. Descateaux, P.; Astudillo, M.F.; Amor, M.B. Assessing the life cycle environmental benefits of renewable distributed generation in a context of carbon taxes: The case of the Northeastern American market. Renew. Sustain. Energy Rev. 2016, 53, 1178-1189. [CrossRef]

42. Ouchida, Y.; Goto, D. Environmental research joint ventures and time-consistent emission tax: Endogenous choice of R\&D formation. Econ. Model. 2016, 55, 179-188.

43. Lambertini, L.; Poyago-Theotoky, J.; Tampieri, A. Cournot competition and "green" innovation: An inverted-U relationship. Energy Econ. 2017, 68, 116-123. [CrossRef]

44. Lee, S.H.; Xu, L. Endogenous timing in private and mixed duopolies with emission taxes. J. Econ. 2018, 124, 175-201. [CrossRef]

45. The Difference between a Carbon Tax and an Emissions Tax. Available online: https://www.emissionstax. org/what/carbon-tax/ (accessed on 14 July 2018).

46. Wang, M.; Liu, K.; Choi, T.-M.; Yue, X. Effects of carbon emission taxes on transportation mode selections and social welfare. IEEE Trans. Syst. Man Cybern. 2015, 45, 1413-1423. [CrossRef]

47. Wang, X.; Zhu, Y.; Sun, H.; Jia, F. Production decisions of new and remanufactured products: Implications for low carbon emission economy. J. Clean. Prod. 2018, 171, 1225-1243. [CrossRef]

48. Yang, L.; Hu, X.; Fang, L. Carbon emissions tax policy of urban road traffic and its application in Panjin, China. PLoS ONE 2018, 13, e0196762. [CrossRef] [PubMed] 
49. Liu, Y.; Xing, J.; Li, Y.; Wang, Y.; Wang, L.; Zheng, B.; Tao, D. Effect of carbon equivalent on thermal and mechanical properties of compacted graphite cast iron. Int. J. Mater. Res. 2016, 31, 2516-2523. [CrossRef]

50. Wu, B.; Huang, W.; Liu, P. Carbon reduction strategies based on an NW small-world network with a progressive carbon tax. Sustainability 2017, 9, 1747. [CrossRef]

51. Böhringer, C. Carbon taxes with exemptions in an open economy: A general equilibrium analysis of the German tax initiative. J. Econ. Manag. 1997, 32, 189-203. [CrossRef]

52. Zheng, J.; Qiao, H.; Wang, S. The Effect of Carbon Tax in Aviation Industry on the Multilateral Simulation Game. Sustainability 2017, 9, 1247. [CrossRef]

53. Pereira, V.; Costa, H.G. A literature review on lot size with quantity discounts: 1995-2013. J. Model. Manag. 2015, 10, 341-359. [CrossRef]

54. Alfares, H.K.; Ghaithan, A.M. Inventory and pricing model with price-dependent demand, time-varying holding cost, and quantity discounts. Comput. Ind. Eng. 2016, 94, 170-177. [CrossRef]

55. Rezaee, M.J.; Yousefi, S.; Hayati, J. A multi-objective model for closed-loop supply chain optimization and efficient supplier selection in a competitive environment considering quantity discount policy. J. Ind. Eng. Int. 2017, 13, 199-213. [CrossRef]

56. Shahsavar, A.; Zoraghi, N.; Abbasi, B. Integration of resource investment problem with quantity discount problem in material ordering for minimizing resource costs of projects. Oper. Res. 2018, 18, 1-28. [CrossRef]

57. Demeere, N.; Stouthuysen, K.; Roodhooft, F. Time-driven activity-based costing in an outpatient clinic environment: development, relevance and managerial impact. Health Policy 2009, 92, 296-304. [CrossRef] [PubMed]

58. Szychta, A. Time-driven activity-based costing in service industries. Social Sci. 2010, 1, 49-60.

59. Öker, F.; Adıgüzel, H. Time-driven activity-based costing: An implementation in a manufacturing company. J. Corp. Acc. Financ. 2016, 27, 39-56. [CrossRef]

(C) 2018 by the author. Licensee MDPI, Basel, Switzerland. This article is an open access article distributed under the terms and conditions of the Creative Commons Attribution (CC BY) license (http://creativecommons.org/licenses/by/4.0/). 